\title{
Bariatric surgery versus non-surgical treatment for obesity: a systematic review and meta-analysis of randomised controlled trials
}

\begin{abstract}
Objective To quantify the overall effects of bariatric surgery compared with non-surgical treatment for obesity.

Design Systematic review and meta-analysis based on a random effects model.

Data sources Searches of Medline, Embase, and the Cochrane Library from their inception to December 2012 regardless of language or publication status.

Eligibility criteria Eligible studies were randomised controlled trials with $\geq 6$ months of follow-up that included individuals with a body mass index $\geq 30$, compared current bariatric surgery techniques with non-surgical treatment, and reported on body weight, cardiovascular risk factors, quality of life, or adverse events.

Results The meta-analysis included 11 studies with 796 individuals (range of mean body mass index at baseline 30-52). Individuals allocated to bariatric surgery lost more body weight (mean difference -26 kg (95\% confidence interval -31 to -21$)$ ) compared with non-surgical treatment, had a higher remission rate of type 2 diabetes (relative risk 22.1 (3.2 to 154.3) in a complete case analysis; 5.3 (1.8 to 15.8) in a conservative analysis assuming diabetes remission in all non-surgically treated individuals with missing data) and metabolic syndrome (relative risk 2.4 (1.6 to 3.6) in complete case analysis; 1.5 (0.9 to 2.3) in conservative analysis), greater improvements in quality of life and reductions in medicine use (no pooled data). Plasma triglyceride concentrations decreased more (mean difference $-0.7 \mathrm{mmol} / \mathrm{L}(-1.0$ to -0.4$)$ and high density lipoprotein cholesterol concentrations increased more (mean difference $0.21 \mathrm{mmol} / \mathrm{L}(0.1$ to 0.3$)$ ). Changes in blood pressure and
\end{abstract}

total or low density lipoprotein cholesterol concentrations were not significantly different. There were no cardiovascular events or deaths reported after bariatric surgery. The most common adverse events after bariatric surgery were iron deficiency anaemia (15\% of individuals undergoing malabsorptive bariatric surgery) and reoperations (8\%).

Conclusions Compared with non-surgical treatment of obesity, bariatric surgery leads to greater body weight loss and higher remission rates of type 2 diabetes and metabolic syndrome. However, results are limited to two years of follow-up and based on a small number of studies and individuals.

Systematic review registration PROSPERO CRD42012003317 (www. crd.york.ac.uk/PROSPERO).

\section{Introduction}

Obesity is one of the greatest public health problems in industrialised countries. ${ }^{12}$ In the US, UK, and Australia, for instance, the prevalence of obesity (body mass index (weight $(\mathrm{kg}) /\left(\right.$ height $\left.(\mathrm{m})^{2}\right)>30$ ) has more than doubled in the past 25 years. ${ }^{2}$ Currently, $67 \%$ of the US population is either overweight or obese, and in most European countries the prevalence ranges between $40 \%$ and $50 \%{ }^{3}$ Obesity is associated with an increased risk for type 2 diabetes, hypertension, dyslipidaemia, cardiovascular diseases, musculoskeletal disorders (such as osteoarthritis), certain types of cancer, and mortality. ${ }^{4}$ This entails huge healthcare costs due to obesity. ${ }^{5}$

Treatment options for obesity include non-surgical treatment and bariatric surgery. The non-surgical treatment is usually a 
multicomponent approach comprising behavioural therapy, dietary changes with the main aim of reducing energy intake, increasing physical activity, and various pharmacotherapies. ${ }^{6}$ The most commonly used bariatric surgery techniques are Roux-en-Y gastric bypass, sleeve gastrectomy, and laparoscopic adjustable gastric banding. ${ }^{7-9}$ Current guidelines recommend evaluation of bariatric surgery for individuals with a body mass index $>40$ or $>35$ with serious comorbidities related to obesity. ${ }^{8}{ }^{10}$ A Cochrane review from 2009 suggested greater body weight loss, improvement in the control of comorbidities, and better quality of life in obese patients who underwent bariatric surgery compared with non-surgical treatment for obesity. ${ }^{11}$ However, the review included only a qualitative summary of three randomised controlled trials. ${ }^{112}$ Since then several further randomised controlled trials have been completed. The present systematic review and meta-analysis aims at comprehensively summarising and quantifying the effects of bariatric surgery compared with non-surgical treatment in randomised controlled trials on weight loss, cardiovascular risk factors, adverse events, and quality of life in individuals with a body mass index $\geq 30$.

\section{Methods \\ Eligibility criteria}

Studies were eligible if they were randomised controlled trials ( $\geq 6$ months' follow-up); included individuals with a body mass index $\geq 30$; investigated currently used laparoscopic or open bariatric surgery techniques (Roux-en-Y gastric bypass, adjustable gastric banding, sleeve gastrectomy, biliopancreatic diversion, or biliopancreatic diversion with duodenal switch); investigated as comparator non-surgical treatment for obesity (diet, weight reducing drugs, behavioural therapy, or any combination thereof); and reported changes in body weight; body fat mass; fat-free mass; waist circumference; blood pressure; fasting levels of plasma total cholesterol, high density and low density lipoproteins, triglycerides, glycated haemoglobin $\mathrm{HbA}_{1 \mathrm{c}}$, and glucose; quality of life from baseline to the end of follow-up; remission of type 2 diabetes, metabolic syndrome, or hypertension; reduction in the use of antihypertensive, antidiabetic, or lipid lowering drugs; and adverse events.

\section{Information sources and searches}

We aimed to identify all relevant studies regardless of language or publication status. We searched Medline (via Pubmed), Embase, and the Cochrane Library from their inception to June 2013 (for search strategies see appendix tables 1 and 2 on bmj.com). We also searched trial registries of ongoing trials (appendix table 3). Additionally, we contacted authors to obtain additional data.

\section{Study selection}

Two reviewers independently screened retrieved database files and the full text of potentially eligible studies for relevance. Disagreement was resolved by consensus.

\section{Data collection and risk of bias assessment}

Two reviewers abstracted data independently into a pilot tested, data abstraction form on general study characteristics, baseline characteristics of individuals, outcomes mentioned above, and assessed risk of bias for each included study at the level of selected outcomes. ${ }^{13} \mathrm{We}$ assessed publication bias by creating a funnel plot for the mean differences in body weight change. ${ }^{14}$ Disagreement was resolved by consensus.

\section{Data synthesis and analysis}

Relative risks (with 95\% confidence intervals) were calculated for dichotomous data, and mean differences were calculated for continuous data. Statistical analyses were performed using RevMan 5.1. Outcome measures were quantitatively summarised, if possible, using a random effects model. For some studies the mean change from baseline to end of follow-up was calculated.

Missing standard deviations were derived from other statistics, such as $\mathrm{P}$ values or confidence intervals if needed. ${ }^{15}$ When a $\mathrm{P}$ value was reported as, for example, $\mathrm{P} \leq 0.001, \mathrm{P}=0.001$ was assumed. ${ }^{13}$ Heterogeneity among combined study results was assessed by Cochran's Q test and by the degree of inconsistency $\left(\mathrm{I}^{2}\right) .{ }^{13}$ Furthermore, subgroup and sensitivity analyses were performed.

In order to investigate the influence of missing data on the pooled effect sizes for diabetes and metabolic syndrome remission, we conducted both a complete case and a conservative case scenario analysis. In the conservative case scenario, we treated all patients with missing data in the non-surgical treatment group as if they achieved remission and those in the bariatric surgery group as if they did not. The terms remission of type 2 diabetes or metabolic syndrome were used as defined by study authors (appendix table 4).

\section{Results}

The study selection process is summarised in figure $1 \Downarrow$. From a total of 1988 records, 11 studies $(n=796)$ were eligible and included in the meta-analysis. A list of included studies with the corresponding publications, and a table summarising ongoing trials $(n=18)$ is provided in appendix tables 3 and 5. Additional data or information for risk of bias assessment were obtained for the studies Mingrone 2012, ${ }^{16}$ Mingrone 2002, ${ }^{17}$ Schauer $2012,{ }^{18}$ Ikramuddin $2013,{ }^{19}$ and Reis $2010^{20}$ by contacting the study authors. Standard deviations were derived from the $95 \%$ confidence intervals for O'Brien $2010^{21}$ and Dixon 2012. ${ }^{22} \mathrm{We}$ imputed standard deviations for Mingrone 2002, ${ }^{17}$ O'Brien $2006,{ }^{23}$ and Liang $2013^{24}$ by taking the median standard deviation of the respective groups of the other studies, because no other statistic was available.

\section{General study characteristics}

The 11 studies included were conducted in Australia (4), Italy (2), Denmark (1), US (1), China (1), Brazil (1), and in the US and Taiwan (1) (appendix table 6). Five studies included only individuals with type 2 diabetes, ${ }^{17-19} 2425$ three studies included only individuals who had made serious attempts at weight loss before, ${ }^{21-23}$ and one study included only individuals with obstructive sleep apnoea. ${ }^{22}$ Bariatric surgery was compared with non-surgical treatment, which generally comprised alterations in dietary intake, physical activity, behavioural or lifestyle modification, and pharmacotherapy. Study groups are described in appendix table 7. Only four studies ${ }^{17} 192122$ quantitatively reported restrictions in energy intake. In four studies ${ }^{18} 1922$ the same treatment for the non-surgical group was also offered to the surgical groups, and in one study an extensive weight loss programme was applied for four months before bariatric surgery. ${ }^{20}$ One study had a follow-up of 40 weeks, ${ }^{26}$ four studies had a follow-up of one year, ${ }^{17-19}{ }^{24}$ and all other studies had a follow-up of two years. The studies comprised two three-arm 
studies and nine two-arm studies, with five of them evaluating the effects of laparoscopic adjustable gastric banding, ${ }^{21-23} 2526$ five evaluating Roux-en-Y gastric bypass, ${ }^{16}{ }^{18-20} 24$ one evaluating sleeve gastrectomy, ${ }^{18}$ and two evaluating biliopancreatic diversion. ${ }^{16}{ }^{17}$ Individuals' baseline characteristics are presented in table $1 \Downarrow$. One study ${ }^{21}$ included adolescents (mean age range 16-17 years); the other studies were of adults (mean age range 37-51 years across studies). Mean body mass index ranged from 30 to 52 across studies. One study reported only ranges of body mass index (40-56) and age (40-56 years) at baseline. ${ }^{26}$

\section{Risk of bias assessment}

Results of the risk of bias assessment are presented in tables $2 \Downarrow$ and $3 \Downarrow$ and in more detail in appendix table 8 . The sequence generation for randomisation was adequate in all studies but one. ${ }^{26}$ Concealment of group allocation was unclear in five studies. ${ }^{21} 22$ 24-26 In all studies, patients and healthcare providers were not blinded. Data collectors, outcome adjudicators, and data analysts were not blinded as far as outcomes relevant to this review are concerned in two studies, ${ }^{18}{ }^{20}$ blinded in three studies, ${ }^{16} 17$ and unclear in the remaining six studies. In all studies patients were analysed in the groups to which they were randomised. In four studies not all individuals randomised were finally analysed. ${ }^{16} 212324$ Across studies, the percentage of individuals not analysed ranged from $3 \%$ to $28 \%$ in the non-surgical treatment group and from $1 \%$ to $14 \%$ in the bariatric surgery group.

Missing continuous outcome data were not addressed appropriately (either not addressed at all or use of baseline data carried forward analysis) in four studies. ${ }^{21}{ }^{23-25}$ Missing data on diabetes remission were addressed in three of four studies reporting on this outcome. ${ }^{16}{ }^{18}{ }^{25}$ However, the reported risk ratio was based on the complete data set. Missing data on metabolic syndrome remission were not addressed in three of five studies. $^{21} 2325$

All but three studies ${ }^{20}{ }^{24}$ were free of selective reporting. In two of the studies adverse events were poorly reported, ${ }^{20}{ }^{24}$ and the other study was only available as an abstract. ${ }^{26}$

Publication bias was assessed descriptively for the outcome of body weight loss (appendix fig 1). Because of the limited number of studies, publication bias was judged as unclear.

\section{Outcomes}

\section{Body weight}

Changes in body weight were pooled for 10 studies; one study ${ }^{24}$ reported only on body mass index. Individuals after bariatric surgery lost more body weight (mean difference $-26 \mathrm{~kg}(95 \%$ confidence interval -31 to -21$), \mathrm{P}<0.001$ ) than individuals after non-surgical treatment (fig $2 \Downarrow$ ). Heterogeneity among studies was high $\left(\mathrm{I}^{2}=95 \%\right)$. Excluding studies with $\leq 1$ year of follow-up did not change the effect size (mean difference $-27 \mathrm{~kg}$ ( -36 to $-18)$ ) nor the degree of heterogeneity $\left(\mathrm{I}^{2}=96 \%\right)$.

Subgroup analyses-Body weight loss was not significantly different between adjustable gastric banding and other bariatric surgery techniques combined (difference of the mean difference $-7 \mathrm{~kg}, \mathrm{P}=0.29$ ) (fig $2 \Downarrow$ ), nor between adjustable gastric banding and Roux-en-Y gastric bypass (difference of the changes in mean difference $-6 \mathrm{~kg}, \mathrm{P}=0.230$ ) (fig $3 \Downarrow$ ). Individuals in trials with a mean baseline body mass index $\geq 40$ lost more body weight than individuals in trials with a mean baseline body mass index $<40$ (difference of the mean difference $-13 \mathrm{~kg}, \mathrm{P}<0.001$ ) (appendix fig 2). Body weight loss was not significantly different between surgically treated individuals who additionally received the same treatment as the non-surgical treatment group (difference of the changes in mean difference $-6 \mathrm{~kg}, \mathrm{P}=0.24$ ) and individuals after bariatric surgery who received a different accompanying treatment (appendix fig 3). Across all subgroup analyses, statistical heterogeneity remained high.

\section{Waist circumference}

Changes in waist circumference were available for six studies. ${ }^{18} 19{ }^{21-2325}$ Waist circumference decreased more after bariatric surgery than after non-surgical treatment (mean difference $-16 \mathrm{~cm}(-18$ to -13$), \mathrm{P}<0.001)$. Heterogeneity was moderate (fig $4 \Downarrow$ ).

\section{Fat-free mass and fat mass}

Changes in fat-free mass and fat mass were pooled for two studies. ${ }^{17}{ }^{27}$ Individuals after bariatric surgery lost more fat-free mass (mean difference $-5 \mathrm{~kg}(-11$ to -1$), \mathrm{P}=0.01)$ and more fat mass (mean difference $-18 \mathrm{~kg}(-31$ to -5$), \mathrm{P}=0.001)$ than after non-surgical treatment (appendix fig 4A and 4B).

\section{Diabetes remission}

The relative risk of type 2 diabetes remission was pooled for four studies. ${ }^{16182425}$ All of them included only individuals with type 2 diabetes at baseline. Different definitions for diabetes remission were used, and one study ${ }^{24}$ did not report a definition (appendix table 4). Based on the complete case analysis, the relative risk to achieve diabetes remission was 22 times higher (relative risk 22.1 (3.2 to 154.3 ), $\mathrm{P}=0.002$ ) compared with non-surgical treatment (fig $5 \Downarrow$ ). Heterogeneity was high. Based on the conservative case scenario, the relative risk to achieve diabetes remission was five times higher (relative risk 5.3 (1.8 to 15.8$), \mathrm{P}=0.003$ ) after bariatric surgery. Heterogeneity was high (appendix fig 5).

\section{Metabolic syndrome remission}

The relative risk of metabolic syndrome remission was available for five studies. ${ }^{18} 21232528$ All studies included mixed populations of individuals with and without metabolic syndrome (table $1 \Downarrow$ ). Three studies used the same definition for metabolic syndrome remission, one definition was adapted to adolescents, and the other study did not report on a definition (appendix table 4). Based on the complete case analysis, the relative risk to achieve metabolic syndrome remission was 2.4 times higher (relative risk 2.4 (1.6 to 3.6), $\mathrm{P}<0.001$ ) compared with non-surgical treatment. Heterogeneity was moderate (fig $6 \Downarrow$ ). Based on the conservative case scenario, there was no significant difference in metabolic syndrome remission between bariatric surgery and non-surgical treatment (relative risk 1.5 (0.9 to 2.3), $\mathrm{P}=0.12$ ). Heterogeneity was high (appendix fig 6).

\section{Hypertension remission}

This was not addressed by any of the studies.

\section{Blood pressure}

The mean changes in systolic blood pressure were available for seven studies ${ }^{16} 1821242528$ and changes in diastolic blood pressure for six studies. ${ }^{16} 1819212528$ Changes in systolic (mean difference $-8.8 \mathrm{~mm} \mathrm{Hg}$ ( -26.2 to 8.5$), \mathrm{P}=0.32$ ) and diastolic (mean difference $-0.4 \mathrm{~mm} \mathrm{Hg}$ ( -2.9 to 2.1 ), $\mathrm{P}=0.77$ ) blood pressure were not significantly different between bariatric surgery and non-surgical treatment. Heterogeneity was high for systolic and moderate for diastolic blood pressure (appendix fig $7 \mathrm{~A}$ and $7 \mathrm{~B})$. 


\section{Triglyceride concentrations}

The mean changes in triglyceride concentrations were available for eight studies. ${ }^{16-1921242528}$ Triglycerides decreased more after bariatric surgery (mean difference $-0.7 \mathrm{mmol} / \mathrm{L}(-1.0$ to -0.4$)$, $\mathrm{P}<0.001)$ than after non-surgical treatment. Heterogeneity was high (fig $7 \Downarrow$ ).

\section{Plasma cholesterol}

The mean changes in total cholesterol concentration were pooled for seven studies. ${ }^{16-19} 2425{ }^{28}$ Change of cholesterol was not significantly different between bariatric surgery and non-surgical treatment (mean difference $-0.4 \mathrm{mmol} / \mathrm{L}$ ( -0.8 to 0.00 ), $\mathrm{P}=0.05$ ). Heterogeneity was high (fig $8 \Downarrow$ ).

Changes in high density lipoprotein cholesterol concentration were available for eight studies. ${ }^{16-19} 21242528$ Concentration increased more after bariatric surgery than after non-surgical treatment (mean difference $0.21 \mathrm{mmol} / \mathrm{L}(0.1$ to 0.3$), \mathrm{P}<0.001)$. Heterogeneity was high (fig $9 \Downarrow$ ).

The mean changes in low density lipoprotein cholesterol concentration were available for five studies. ${ }^{16-19}{ }^{24}$ Changes in concentration were not significantly different between the two groups (mean difference $-0.6 \mathrm{mmol} / \mathrm{L}(-1.2$ to -0.01$), \mathrm{P}=0.06$ ). Heterogeneity was high (fig $10 \Downarrow$ ).

\section{Plasma glucose}

Mean changes in fasting glucose levels were available for seven studies. ${ }^{16-19} 212528$ Glucose levels decreased more after bariatric surgery than after non-surgical treatment (mean difference -1.5 $\mathrm{mmol} / \mathrm{L}(-2.1$ to -0.8$), \mathrm{P}<0.001)$. Heterogeneity was high (fig $11 \Downarrow$. and appendix fig 9). Glucose levels decreased more after Roux-en-Y gastric bypass, sleeve gastrectomy, or biliopancreatic diversion than after adjustable gastric banding (test for subgroup differences $\mathrm{P}<0.001$ ) for all patients (fig $11 \Downarrow$ ) as well as for studies which included patients with diabetes only (appendix fig 8).

Mean changes in glycated haemoglobin $\mathrm{HbA}_{1 \mathrm{c}}$ were pooled for the five studies including only individuals with type 2 diabetes. ${ }^{1618192425} \mathrm{HbA}_{1 \mathrm{c}}$ decreased more after bariatric surgery than after non-surgical treatment (mean difference $-1.5 \%(-1.9$ to -1.1 ), $\mathrm{P}<0.001$ ). Heterogeneity was moderate (fig $12 \Downarrow$ ).

\section{Medication use}

Medication use was reported by four studies. ${ }^{18} 192425$ In Schauer $2012^{18}$ the goal of medical management was to reach an $\mathrm{HbA}_{1 \mathrm{c}}$ $\leq 6 \%$, a blood pressure of $\leq 130 / 80 \mathrm{~mm} \mathrm{Hg}$, and a low density lipoprotein cholesterol level of $<2.6 \mathrm{mmol} / \mathrm{L}$. In Dixon $2008^{25}$ drug treatment was determined by an experienced diabetologist on an individual basis. In Liang $2013^{24}$ the aim was to reach an $\mathrm{HbA}_{\mathrm{lc}}<7 \%$ and a blood pressure of $\leq 140 / 90 \mathrm{~mm} \mathrm{Hg}$. In Ikramuddin $2013^{19}$ the aim was to reach an $\mathrm{HbA}_{1 \mathrm{c}}<7 \%$, low density lipoprotein cholesterol level $<2.6 \mathrm{mmol} / \mathrm{L}$, and a systolic blood pressure of $\leq 130 \mathrm{~mm} \mathrm{Hg}$.

Ikramuddin 2013 reported the average change in antidiabetic, antihypertensive, and lipid lowering drug use combined. The group treated by Roux-en-Y gastric bypass used 3.0 (95\% confidence interval 2.3 to 3.6) fewer drugs than the non-surgical treatment group at one year of follow-up. ${ }^{19}$ Schauer 2012 reported that the number of patients receiving antidiabetic drugs decreased from 42 to 10 after Roux-en-Y gastric bypass (-76\%) and from 41 to 19 after sleeve gastrectomy ( $-54 \%)$, but did not change after non-surgical treatment at one year of follow-up. ${ }^{18}$ Liang 2013 reported that oral hypoglycaemic agents and insulin use were stopped in all patients after Roux-en-Y gastric bypass. ${ }^{24}$
Similarly, Dixon 2008 reported that the number of patients receiving antidiabetic drugs decreased from 28 to three after adjustable gastric banding (-89\%) and from 26 to 18 after non-surgical treatment $(-18 \%)$ at two years of follow-up. ${ }^{25}$

Schauer 2012 reported, that the number of patients receiving antihypertensive drugs decreased from 39 to 16 after Roux-en-Y gastric bypass (-59\%), from 33 to 13 after sleeve gastrectomy $(-61 \%)$, and from 31 to $30(-3 \%)$ after non-surgical treatment. ${ }^{18}$ Similarly, Liang 2013 reported that antihypertensive drug use decreased after Roux-en-Y gastric bypass and remained unchanged after non-surgical treatment. ${ }^{24}$ In Dixon 2008, the number of patients receiving antihypertensive drugs decreased from 20 to six after adjustable gastric banding $(-70 \%)$ but not after non-surgical treatment. ${ }^{25}$

Schauer 2012 reported that the number of patients receiving lipid lowering agents decreased from 43 to 13 after Roux-en-Y gastric bypass $(-70 \%)$ and from 38 to 19 after sleeve gastrectomy $(-50 \%)$, but increased from 34 to 36 after non-surgical treatment $(6 \%) .{ }^{18}$ Patients receiving lipid lowering agents after adjustable gastric banding decreased from 12 to four $(-67 \%)$ and from eight to seven after non-surgical treatment $(-13 \%){ }^{25}$

\section{Quality of life}

Quality of life was reported in three studies. Two studies used the SF-36 (Medical Outcomes Trust Short Form 36) questionnaire. In one of these studies, ${ }^{22}$ three of eight domains (physical role, general health, and vitality) improved more after bariatric surgery, as did five of eight domains in the other study (physical function, physical role, general health, energy, and emotional role). ${ }^{23}$ In the third study, ${ }^{21}$ which included adolescents, the Child Health Questionnaire was used. Here, two of eight domains (general health and change in health) improved more after bariatric surgery.

\section{Adverse events}

Adverse events are listed in appendix table 9. All but one study ${ }^{17}$ reported adverse events in the publication, but the missing data were obtained on request. There were no perioperative deaths, cardiovascular events, or deaths during follow-up. One Roux-en-Y gastric bypass patient who developed a leak from the jejuno-jejunostomy suffered anoxic brain injury, lower extremity amputation, and long term disability. After bariatric surgery, 21/261 (8\%) individuals required reoperations (15/124 after adjustable gastric banding, 4/69 after Roux-en-Y gastric bypass, 1/49 after sleeve gastrectomy, 1/19 after biliopancreatic diversion). Three individuals developed hernia (1 after Roux-en-Y gastric bypass, 1 after biliopancreatic diversion, 1 after adjustable gastric banding) and five developed pneumonia (2 Roux-en-Y gastric bypass, 3 adjustable gastric banding). Other adverse events occurred after bariatric surgery as well as after non-surgical treatment: 29/194 (15\%) developed iron deficiency anaemia after bariatric surgery other than adjustable gastric banding (21/126 Roux-en-Y gastric bypass, 6/49 sleeve gastrectomy, 2/19 biliopancreatic diversion) and 3/169 (2\%) after non-surgical treatment. Cholecystitis requiring cholecystectomy occurred in 4/261 (1.5\%) of surgically and in $5 / 169(3 \%)$ of non-surgically treated individuals. Depression developed in 1/261 of surgically treated and in 1/55 of non-surgically treated individuals. 


\section{Discussion Principal findings}

This systematic review and meta-analysis demonstrates that bariatric surgery is more efficient than non-surgical treatment for obesity for up to two years of follow-up. Bariatric surgery led to greater body weight loss, higher rates of remission of type 2 diabetes and metabolic syndrome, greater improvements in quality of life, and greater reductions in use of antidiabetic, antihypertensive, and lipid lowering drugs. Furthermore, waist circumference and fasting levels of plasma glucose, $\mathrm{HbA}_{1 \mathrm{c}}$, and triglycerides decreased more, and high density lipoprotein cholesterol levels increased more, after bariatric surgery. There was no significant difference between bariatric surgery and non-surgical treatment for changes in blood pressure and levels of total or low density lipoprotein cholesterol (though some studies reported concomitant reductions in drug use for these conditions). There were no perioperative deaths or cardiovascular events reported during follow-up. The most common adverse events after bariatric surgery were iron deficiency anaemia for individuals undergoing malabsorptive bariatric surgery $(15 \%)$ and reoperations $(8 \%)$.

\section{Strengths and limitations of study}

The strength of this study is its comprehensive approach to identify all randomised controlled trials comparing bariatric surgery with non-surgical treatment for obesity. It quantitatively summarises the currently available evidence on a large spectrum of health outcomes. Our results proved to be robust across various sensitivity analyses and across most subgroups.

We conducted two analyses for remission rates of type 2 diabetes and metabolic syndrome: a complete case and a conservative case scenario. Both types of analysis favoured bariatric surgery over non-surgical treatment concerning remission of type 2 diabetes, but the assumptions made about missing data affected the effect size substantially. Concerning metabolic syndrome remission, only the complete case analysis favoured bariatric surgery.

Though the differences in body weight loss might explain some of the greater improvements in diabetes remission after bariatric surgery compared with non-surgical treatment, changes in the gastrointestinal anatomy, gut hormones, and regulatory factors of energy homeostasis may be the primary mediators..$^{29}{ }^{30}$ This is consistent with the findings that Roux-en-Y gastric bypass and biliopancreatic diversion caused diabetes remission within days to weeks after surgery, before substantial weight loss occurred. ${ }^{31}{ }^{32}$ Whether different definitions used for type 2 diabetes remission (appendix table 4) had an effect was not investigated because of the limited number of studies identified. However, investigators of future trials are encouraged to use a standard definition for diabetes remission. ${ }^{33}$

Our study has several limitations. Summary measures of effect sizes are based on only 11 studies or fewer depending on outcome. Furthermore, the methodological quality of five of these studies suffered from unclear allocation concealment. The risk for attrition bias was high in four studies, and attrition was always higher in the non-surgical treatment group. Under the assumption that patients in the non-surgical treatment group with complete data did better than those with missing data, our results seem to represent a conservative estimate of the benefits of bariatric surgery over non-surgical treatment. As far as body weight loss is concerned, the non-surgical treatment group might have been prone to do worse, because it can be assumed that previous weight loss attempts by similar means (such as food restriction) occurred in participants of all studies. Three of the included trials $\mathrm{s}^{21-23}$ explicitly mentioned that all included individuals were required to have made serious attempts to lose weight before entering the study. Thus, the results presented in our meta-analysis may not apply to individuals without prior weight loss attempts.

All included trials were relatively small, conducted in centres of excellence for bariatric surgery, and limited to a maximum of two years of follow-up. Thus adverse events reported in this meta-analysis may underestimate rates in less specialised centres or in larger trials with broader patient populations, and no conclusions can be drawn for adverse events in the longer term. In addition, it may underestimate rates in obese patients with multiple or severe comorbidities, because such patients were excluded in most of the included trials. It must also be kept in mind that individuals after bariatric surgery must adhere to lifelong micronutrient supplementation after malabsorptive bariatric surgery and are often advised to avoid commonly used drugs such as non-steroidal anti-inflammatory drugs.

Furthermore, harms are often poorly reported in surgical trials and randomised controlled trials in general. ${ }^{34}{ }^{35}$ In a meta-analysis including 14 studies (1 randomised controlled trial and 13 prospective studies) comparing Roux-en-Y gastric bypass with adjustable gastric banding, perioperative mortality was less than $0.5 \%$ for both procedures. ${ }^{36}$ Reported long term reoperation rates (16\% after Roux-en-Y gastric bypass and $24 \%$ after adjustable gastric banding) were two to three times higher than in our meta-analysis. In the observational SOS study, ${ }^{37}$ perioperative mortality for vertical banded gastroplasty, gastric banding, or gastric bypass was $0.25 \%$ and reoperation rate was $3 \% .^{37}$

We do not have information from randomised controlled trials on body weight in the longer term. Large prospective observational studies showed that individuals regained about $7 \%$ of their lost body weight between two and 10 years after Roux-en-Y gastric bypass. ${ }^{37}{ }^{38}$ In contrast, regain of lost body weight in a large trial using lifestyle modification was about $40 \%$ between one and four years of follow-up. ${ }^{39}$

Our meta-analysis could also not investigate the effect of bariatric surgery on cardiovascular morbidity and mortality. A meta-analysis including eight non-randomised trials with 44022 participants and a mean follow-up of 7.5 years showed a reduction in cardiovascular mortality (odds ratio $0.58(95 \%$ confidence interval 0.46 to 0.73 )) and overall mortality (odds ratio 0.7 (0.59 to 0.84$)$ ) after bariatric surgery compared with non-surgical controls. ${ }^{40}$ Thus, the greater improvements in cardiovascular risk factors after bariatric surgery may translate to reduced cardiovascular morbidity and mortality.

We think that, for some meta-analyses, $\mathrm{I}^{2}$ was misleadingly high. Conceptually, $\mathrm{I}^{2}$ represents the ratio of the variability between studies to the variability within studies and is independent from the number of included studies. When the variability within studies is small-represented by narrow confidence intervals - the variability between studies can also be small and the $\mathrm{I}^{2}$ nevertheless high and inflated. ${ }^{41}{ }^{42}$ This is shown vividly, for example, by the weight outcome (fig $2 \Downarrow$ ). Here, the intuitive, and correct, interpretation of the results is that they consistently show a large effect. The high $\mathrm{I}^{2}$ reflects the uncertainty that remains between the lowest weight loss $(\sim 21 \mathrm{~kg})$ and the largest $(\sim 31 \mathrm{~kg})$, but the results leave us confident that the true effect lies between these values, and the pooled effect ( $\sim 26 \mathrm{~kg}$ ) provides the best single estimate.

In subgroup analyses comparing adjustable gastric banding with other bariatric surgery techniques (Roux-en-Y gastric bypass, 
sleeve gastrectomy, and biliopancreatic diversion combined) or with Roux-en-Y gastric bypass, there was no significant difference in body weight loss. However, the power of our subgroup analysis to detect differences between adjustable gastric banding and other bariatric surgery techniques was limited by the small number of participants. Furthermore, comparisons are limited to between-study comparisons. In a recent meta-analysis including five randomised controlled trials comparing adjustable gastric banding directly with other bariatric surgery techniques, adjustable gastric banding was associated with less body weight loss. ${ }^{43}$

The results of this meta-analysis apply to a general population of obese individuals below the age of 60 years with a body mass index $\geq 30$. In the included studies, the age ranged from 16 to 60 years, the proportion of females ranged from 0 to $88 \%$, and the body mass index at baseline from 30 to $\geq 55$ (except for two studies $^{18}{ }^{24}$ ). No information was available on ethnicities, except for one study. ${ }^{19}$ Results might be different for specific subgroups. The limited number of studies prevented investigations of differential effects due to age or sex. When studies were stratified by mean baseline body mass index, individuals in trials with a body mass index $\geq 40$ lost more body weight after bariatric surgery than individuals in trials with a body mass index $<40$.

\section{Comparison with other studies}

To our knowledge this is the first meta-analysis of randomised controlled trials directly comparing bariatric surgery with non-surgical treatment for obesity. Our results are supported by two systematic reviews. A Cochrane review from 2009 included three randomised controlled trials and three prospective cohort studies. It showed greater body weight loss and greater improvements in cardiovascular risk factors and quality of life after bariatric surgery compared with non-surgical treatment. ${ }^{11}$ The other systematic review from 2013 included three randomised controlled trials and two prospective cohort studies and had similar results. ${ }^{44}$ Neither review performed a meta-analysis. A network meta-analysis from 2011 pooled changes in body mass index but did not pool changes in body weight. ${ }^{12}$ Unlike our meta-analysis, greater improvements in other health outcomes after bariatric surgery were not found. This may be because the network analysis was based on only one direct comparison of bariatric surgery (biliopancreatic diversion) with non-surgical treatment. ${ }^{12}$

\section{Conclusions}

This meta-analysis provides comprehensive evidence that, compared with non-surgical treatment of obesity, bariatric surgery leads to greater body weight loss and higher remission rates of type 2 diabetes and metabolic syndrome. The most common adverse events after bariatric surgery were iron deficiency anaemia (malabsorptive bariatric surgery) and reoperations. Only few studies reported on quality of life, which suggested greater improvements in surgically treated individuals. Results are limited to two years' follow-up and based on a small number of studies and individuals. The evidence beyond two years of follow-up, in particular on adverse events, cardiovascular diseases, and mortality remains unclear and calls for further research on the topic.

We thank Juliane Schäfer (Institute for Clinical Epidemiology and Biostatistics Basel) for statistical advice; We thank Gordon Guyatt and Diane Heels-Ansdell (Mc Master University, Hamilton, Canada) for comments concerning the statistical heterogeneity observed for some outcomes in this study; and Leonardo Oliveira Reis (Department of Urology, University of Campinas, Sao Paulo, Brazil) and Sayeed Ikramuddin (Department of Surgery, University of Minneapolis) for providing additional outcome data.

Contributors: VLG contributed to the design, did the literature search, checked studies for eligibility, extracted data, did the meta-analysis, and wrote up the manuscript and acts as guarantor. MB gave methodological advice, helped interpret the results, and critically revised the manuscript. DLB, SRK, PRS, and GM were investigators on included trials, provided data for their respective trials, and critically revised the manuscript. HCB critically revised the manuscript. AJN designed the study, checked studies for eligibility, extracted data, wrote up the manuscript, and acts as guarantor. All authors approved the manuscript. Funding: No specific funding, the Institute for Clinical Epidemiology and Biostatistics, University Hospital Basel, is funded by an unrestricted grant from Santéuisse and the Gottfried and Julia Bangerter-Rhyner-Foundation.

The study sponsors did not have any role in the study design, analysis or interpretation of data, in writing of the report or in the decision to submit the article for publication. The researchers were independent from funders.

Competing interests: All authors have completed the ICMJE uniform disclosure form at www.icmje.org/coi_disclosure.pdf (available on request from the corresponding author) and declare: VLG, AJN, MB, and HCB are supported by an unrestricted grant from Santéuisse and the Gottfried and Julia Bangerter-Rhyner-Foundation. DLB is on the advisory boards of Elsevier PracticeUpdate Cardiology, Medscape Cardiology, and Regado Biosciences; is on the boards of directors of Boston VA Research Institute and Society of Cardiovascular Patient Care; is chair of American Heart Association Get With The Guidelines Steering Committee; has received honoraria from American College of Cardiology (editor, Clinical Trials, Cardiosource), Belvoir Publications (editor in chief, Harvard Heart Letter), Duke Clinical Research Institute (clinical trial steering committees), Population Health Research Institute (clinical trial steering committee), Slack Publications (chief medical editor, Cardiology Today's Intervention), WebMD (CME steering committees); is senior associate editor, Journal of Invasive Cardiology; is on data monitoring committees of Duke Clinical Research Institute, Mayo Clinic, and Population Health Research Institute; has received research grants from Amarin, AstraZeneca, Bristol-Myers Squibb, Eisai, Ethicon, Medtronic, Sanofi Aventis, the Medicines Company; and has undertaken unfunded research for FlowCo, PLx Pharma, Takeda. PRS has received payment for board membership from Ethicon Endo-Surgery, Surgiquest, Barosense, RemedyMD, and Stryker; consulting fees from Ethicon Endo-Surgery, Stryker, Gore, and Carefusion; payment for expert testimony from Physicians Review of Surgery; lecture fees from Ethi con Endo-Surgery, Allergan, Cinemed, and Quadrant Healthcom; holds a patent for a medical device to enhance weight loss in codevelopment with the Cleveland Clinic; receives royalties from Springer; has an equity interest in Intuitive Surgical, Barosense, Surgiquest, and RemedyMD; and receives institutional grant support (to the Cleveland Clinic) from Ethicon Endo-Surgery and Bard Davol. Ethical approval: Not required.

Declaration of transparency: The lead author affirms that this manuscript is an honest, accurate, and transparent account of the study being reported; that no important aspects of the study have been omitted; and that any discrepancies from the study as planned and registered have been explained.

Data sharing: No additional data available.

1 Bhatt DL, Steg PG, Ohman EM, Hirsch AT, Ikeda Y, Mas JL, et al. International prevalence, recognition, and treatment of cardiovascular risk factors in outpatients with atherothrombosis. JAMA 2006;295:180-9.

2 Lobstein T, Leach RJ. Tackling obesities: future choices. International comparisons of obesity trends, determinants and responses-evidence review. www.bis.gov.uk/assets/ foresight/docs/obesity/06\%20page.pdf. 


\section{What is already known on this topic}

Numerous observational studies and few randomised controlled trials have compared bariatric surgery with non-surgical treatment for obesity

Individual randomised controlled trials were not powered to detect differences in the effects on multiple health outcomes, and no meta-analysis of randomised controlled trials directly comparing the effects of bariatric surgery versus non-surgical treatment for obesity is available

\section{What this study adds}

This meta-analysis of randomised controlled trials provides summary effect estimates comparing bariatric surgery with non-surgical treatment for obesity on many different health outcomes

Bariatric surgery is more effective in inducing body weight loss and remission of type 2 diabetes and metabolic syndrome. There were no perioperative deaths or cardiovascular events reported after bariatric surgery. The most common adverse events after bariatric surgery were iron deficiency anaemia $(15 \%)$ and reoperations $(8 \%)$

The lack of evidence beyond two years' follow-up, in particular on adverse events, cardiovascular diseases, and mortality calls for further research

3 World Health Organization. WHO global database on body mass index. http://apps.who. int/bmi/index.jsp.

4 Picot J, Jones J, Colquitt JL, Gospodarevskaya E, Loveman E, Baxter L, et al. The clinical effectiveness and cost-effectiveness of bariatric (weight loss) surgery for obesity: a systematic review and economic evaluation. Health Technol Assess 2009;13:1-190, 215-357, iii-iv.

5 Allender S, Rayner M. The burden of overweight and obesity-related ill health in the UK. Obes Rev 2007;8:467-73.

6 National Institute of Health. Clinical guidelines on the identification, evaluation, and treatment of overweight and obesity in adults-the evidence report. www.nhlbi.nih.gov/ guidelines/obesity/ob_gdlns.htm 1998.

7 Papamargaritis D, Pournaras D, le Roux CW. Techniques, assessment, and effectiveness of bariatric surgery in combating obesity. Open Access Surgery 2010;3.

8 Dixon JB, le Roux CW, Rubino F, Zimmet P. Bariatric surgery for type 2 diabetes. Lancet 2012;379:2300-11.

9 Buchwald H, Oien DM. Metabolic/bariatric surgery worldwide 2011. Obes Surg 2013;23:427-36.

10 Poirier P, Cornier MA, Mazzone T, Stiles S, Cummings S, Klein S, et al. Bariatric surgery and cardiovascular risk factors: a scientific statement from the American Heart Association. Circulation 2011;123:1683-701.

11 Colquitt JL, Picot J, Loveman E, Clegg AJ. Surgery for obesity. Cochrane Database Syst Rev 2009;(2):CD003641.

12 Padwal R, Klarenbach S, Wiebe N, Birch D, Karmali S, Manns B, et al. Bariatric surgery: a systematic review and network meta-analysis of randomized trials. Obes Rev 2011;12:602-21.

13 Higgins JPT, Green S. Cochrane handbook for systematic reviews of interventions. Cochrane Collaboration, 2011. www.cochrane.org/training/cochrane-handbook.

14 Egger M, Davey Smith G, Schneider M, Minder C. Bias in meta-analysis detected by a simple, graphical test. BMJ 1997;315:629-34

15 Wiebe N, Vandermeer B, Platt RW, Klassen TP, Moher D, Barrowman NJ. A systematic review identifies a lack of standardization in methods for handling missing variance data. $J$ Clin Epidemiol 2006:59:342-53.

16 Mingrone G, Panunzi S, De Gaetano A, Guidone C, laconelli A, Leccesi L, et al. Bariatric surgery versus conventional medical therapy for type 2 diabetes. $N$ Engl J Med 2012;366:1577-85

17 Mingrone G, Greco AV, Giancaterini A, Scarfone A, Castagneto M, Pugeat M. Sex hormone-binding globulin levels and cardiovascular risk factors in morbidly obese subjects before and after weight reduction induced by diet or malabsorptive surgery. Atherosclerosis 2002;161:455-62.

18 Schauer PR, Kashyap SR, Wolski K, Brethauer SA, Kirwan JP, Pothier CE, et al. Bariatric surgery versus intensive medical therapy in obese patients with diabetes. N Engl J Med 2012;366:1567-76.

19 Ikramuddin S, Korner J, Lee WJ, Connett JE, Inabnet WB, Billington CJ, et al. Roux-en-Y gastric bypass vs intensive medical management for the control of type 2 diabetes, hypertension, and hyperlipidemia: the Diabetes Surgery Study randomized clinical trial. JAMA 2013;309:2240-9.

20 Reis LO, Favaro WJ, Barreiro GC, de Oliveira LC, Chaim EA, Fregonesi A, et al. Erectile dysfunction and hormonal imbalance in morbidly obese male is reversed after gastric bypass surgery: a prospective randomized controlled trial. Int $J$ Androl 2010;33:736-44.

21 O'Brien PE, Sawyer SM, Laurie C, Brown WA, Skinner S, Veit F, et al. Laparoscopic adjustable gastric banding in severely obese adolescents: A randomized trial. JAMA 2010;303:519-26.

22 Dixon JB, Schachter LM, O'Brien PE, Jones K, Grima M, Lambert G, et al. Surgical vs conventional therapy for weight loss treatment of obstructive sleep apnea: a randomized controlled trial. JAMA 2012;308:1142-9.

23 O'Brien PE, Dixon JB, Laurie C, Skinner S, Proietto J, McNeil J, et al. Treatment of mild to moderate obesity with laparoscopic adjustable gastric banding or an intensive medical program: a randomized trial. Ann Intern Med 2006;144:625-33.

24 Liang Z, Wu Q, Chen B, Yu P, Zhao H, Ouyang X. Effect of laparoscopic Roux-en-Y gastric bypass surgery on type 2 diabetes mellitus with hypertension: a randomized controlled trial. Diabetes Res Clin Prac 2013, doi:10.1016/j.diabres.2013.04.005 [epub ahead of print].
25 Dixon JB, O'Brien PE, Playfair J, Chapman L, Schachter LM, Skinner S, et al. Adjustable gastric banding and conventional therapy for type 2 diabetes: a randomized controlled trial. Obstet Gynecol Survey 2008;63:372-3.

26 Heindorff H, Hougaard K, Larsen PN. Laparoscopic adjustable gastric band increases weight loss compared to dietary treatment: a randomized study. Obes Surg 1997;7:300-1.

27 Dixon JB, Strauss BJ, Laurie C, O'Brien PE. Changes in body composition with weight loss: obese subjects randomized to surgical and medical programs. Obesity 2007;15:1187-98.

28 Dixon J, Schachter L, O'Brien P, Jones K, Grima M, Lambert G, et al. Surgical versus conventional therapy for weight loss treatment of obstructive sleep apnea: A randomized controlled trial. Obesity Res Clin Prac 2012;6:29.

29 Hage MP, Safadi B, Salti I, Nasrallah M. Role of gut-related peptides and other hormones in the amelioration of type 2 diabetes after Roux-en-Y gastric bypass surgery. ISRN Endocrinol 2012;2012:504756.

30 Rubino F, Schauer PR, Kaplan LM, Cummings DE. Metabolic surgery to treat type 2 diabetes: clinical outcomes and mechanisms of action. Annu Rev Med 2010;61:393-411.

31 Schauer PR, Ikramuddin S, Gourash W, Ramanathan R, Luketich J. Outcomes after laparoscopic Roux-en-Y gastric bypass for morbid obesity. Annal Surg 2000;232:515-29.

32 Pories WJ, Swanson MS, MacDonald KG, Long SB, Morris PG, Brown BM, et al. Who would have thought it? An operation proves to be the most effective therapy for adult-onset diabetes mellitus. Annal Surg 1995;222:339-50; discussion 50-2.

33 Pournaras DJ, Aasheim ET, Sovik TT, Andrews R, Mahon D, Welbourn R, et al. Effect of the definition of type II diabetes remission in the evaluation of bariatric surgery for metabolic disorders. Br J Surg 2012;99:100-3.

34 Sinha S, Sinha S, Ashby E, Jayaram R, Grocott MP. Quality of reporting in randomized trials published in high-quality surgical journals. J Am Coll Surg 2009;209:565-71 e1.

35 Golder S, Loke YK, Bland M. Meta-analyses of adverse effects data derived from randomised controlled trials as compared to observational studies: methodological overview. Plos Med 2011;8(5).

36 Tice JA, Karliner L, Walsh J, Petersen AJ, Feldman MD. Gastric banding or bypass? A systematic review comparing the two most popular bariatric procedures. Am J Med 2008;121:885-93.

37 Sjostrom L. Review of the key results from the Swedish Obese Subjects (SOS) trial: a prospective controlled intervention study of bariatric surgery. J Intern Med 2013;273:219-34.

38 Adams TD, Davidson LE, Litwin SE, Kolotkin RL, LaMonte MJ, Pendleton RC, et al. Health benefits of gastric bypass surgery after 6 years. JAMA 2012;308:1122-31.

39 Diabetes Prevention Program Research G, Knowler WC, Fowler SE, Hamman RF, Christophi CA, Hoffman HJ, et al. 10-year follow-up of diabetes incidence and weight loss in the Diabetes Prevention Program Outcomes Study. Lancet 2009;374:1677-86.

40 Pontiroli AE, Morabito A. Long-term prevention of mortality in morbid obesity through bariatric surgery. a systematic review and meta-analysis of trials performed with gastric banding and gastric bypass. Ann Surg 2011;253:484-7.

41 Rucker G, Schwarzer G, Carpenter JR, Schumacher M. Undue reliance on I(2) in assessing heterogeneity may mislead. BMC Med Res Methodol 2008;8:79.

42 Ioannidis JP. Interpretation of tests of heterogeneity and bias in meta-analysis. J Eval Clin Prac 2008;14:951-7.

43 Chakravarty PD, McLaughlin E, Whittaker D, Byrne E, Cowan E, Xu K, et al. Comparison of laparoscopic adjustable gastric banding (LAGB) with other bariatric procedures; a systematic review of the randomised controlled trials. Surgeon 2012;10:172-82.

44 Maggard-Gibbons M, Maglione M, Livhits M, Ewing B, Maher AR, Hu J, et al. Bariatric surgery for weight loss and glycemic control in nonmorbidly obese adults with diabetes: a systematic review. JAMA 2013;309:2250-61.

\section{Accepted: 03 September 2013}

\section{Cite this as: BMJ 2013;347:f5934}

This is an Open Access article distributed in accordance with the Creative Commons Attribution Non Commercial (CC BY-NC 3.0) license, which permits others to distribute, remix, adapt, build upon this work non-commercially, and license their derivative works on different terms, provided the original work is properly cited and the use is non-commercial. See: http://creativecommons.org/licenses/by-nc/3.0/. 


\section{Tables}

\begin{tabular}{|c|c|c|c|c|c|c|c|c|c|c|}
\hline \multirow[b]{2}{*}{ Study } & \multirow[b]{2}{*}{ Group } & \multirow{2}{*}{$\begin{array}{c}\text { No of } \\
\text { patients } \\
\text { randomised }\end{array}$} & \multirow[b]{2}{*}{$\begin{array}{c}\text { Mean (SD) } \\
\text { age (years) }\end{array}$} & \multirow[b]{2}{*}{$\begin{array}{c}\text { Female } \\
(\%)\end{array}$} & \multirow[b]{2}{*}{$\begin{array}{c}\text { Mean (SD) } \\
\text { BMI }\end{array}$} & \multirow{2}{*}{$\begin{array}{l}\text { Mean (SD) } \\
\text { body weight } \\
\quad(\mathrm{kg})\end{array}$} & \multicolumn{2}{|c|}{ Type 2 diabetes } & \multirow{2}{*}{$\begin{array}{c}\text { Metabolic } \\
\text { syndrome } \\
(\%)\end{array}$} & \multirow[b]{2}{*}{$\begin{array}{l}\text { Hypertensior } \\
(\%)\end{array}$} \\
\hline & & & & & & & $\begin{array}{l}\text { Prevalence } \\
(\%)\end{array}$ & $\begin{array}{c}\text { Duration } \\
\text { (years) }\end{array}$ & & \\
\hline \multirow[t]{2}{*}{$\begin{array}{l}\text { Mingrone } \\
2012^{16}\end{array}$} & $\begin{array}{c}\text { Bariatric surgery } \\
(\mathrm{BPD}+\mathrm{RYGB})^{*}\end{array}$ & 40 & $43.4(7.8)$ & 55 & $45.0(6.5)$ & $133.9(26.8)$ & 100 & 6 & NR & NR \\
\hline & Control & 20 & $43.5(7.3)$ & 50 & $45.1(7.8)$ & $136.4(21.9)$ & 100 & 6 & NR & NR \\
\hline \multirow[t]{2}{*}{$\begin{array}{l}\text { Schauer } \\
2012^{18}\end{array}$} & $\begin{array}{c}\text { Bariatric surgery } \\
(\mathrm{RYGB}+\mathrm{SG})^{\star}\end{array}$ & 100 & $48.1(8.1)$ & 68 & $36.6(3.6)$ & $103.8(15.7)$ & 100 & 8 & 92 & 65 \\
\hline & Control & 50 & $49.7(7.4)$ & 62 & $36.8(3.0)$ & $106.5(14.7)$ & 100 & 9 & 92 & 60 \\
\hline \multirow[t]{2}{*}{ Reis $2010^{20}$} & $\begin{array}{c}\text { Bariatric surgery } \\
\text { (RYGB) }\end{array}$ & 10 & $36.7(11.5)$ & 0 & $\begin{array}{l}55.7(7.8), \\
43.1(4.7) \dagger\end{array}$ & $\begin{array}{c}168.6(28.2) \\
130.6(18.3) \dagger\end{array}$ & NR & NR & NR & NR \\
\hline & Control & 10 & $42.2(11.0)$ & 0 & $\begin{array}{l}54.0(6.1) \\
51.9(5.7) \dagger\end{array}$ & $\begin{array}{c}160.4(20.1) \\
154.2(19.3) \dagger\end{array}$ & NR & NR & NR & NR \\
\hline \multirow[t]{2}{*}{$\begin{array}{l}\text { Ikramuddin } \\
2013^{19}\end{array}$} & $\begin{array}{c}\text { Bariatric surgery } \\
\text { (RYGB) }\end{array}$ & 60 & $49(9)$ & 63 & $34.9(3.0)$ & $98.8(14.0)$ & 100 & $8.9(6.1)$ & NR & NR \\
\hline & Control & 60 & $49(8)$ & 34 & $34.3(3.1)$ & $97.9(17.0)$ & 100 & $9.1(5.6)$ & NR & NR \\
\hline \multirow[t]{2}{*}{$\begin{array}{l}\text { Liang } \\
2013^{24}\end{array}$} & $\begin{array}{c}\text { Bariatric surgery } \\
\text { (RYGB) }\end{array}$ & 31 & $50.8(5.4)$ & 29 & $30.5(0.9)$ & $82.0(3.5)$ & 100 & $7.4(1.7)$ & NR & 100 \\
\hline & $\begin{array}{c}\text { Control } \\
\text { (control+control } \\
\text { plus exenatide) }{ }^{*}\end{array}$ & 70 & $51.4(6.2)$ & 31 & $30.3(1.7)$ & $81.5(4.3)$ & 100 & $7.2(1.7)$ & NR & 100 \\
\hline \multirow[t]{2}{*}{$\begin{array}{l}\text { O'Brien } \\
2006^{23}\end{array}$} & $\begin{array}{c}\text { Bariatric surgery } \\
\text { (AGB) }\end{array}$ & 40 & $41.8(6.4)$ & 75 & $33.7(1.8)$ & $96.1(11.9)$ & NR & NR & 38 & 18 \\
\hline & Control & 40 & $40.7(7.0)$ & 77 & $33.5(1.4)$ & $93.6(11.9)$ & NR & NR & 38 & 23 \\
\hline \multirow[t]{2}{*}{$\begin{array}{l}\text { O'Brien } \\
2010^{21}\end{array}$} & $\begin{array}{c}\text { Bariatric surgery } \\
\text { (AGB) }\end{array}$ & 25 & $16.5(1.4)$ & 64 & $42.3(6.1)$ & $120.7(25.3)$ & NR & NR & 36 & NR \\
\hline & Control & 25 & $16.6(1.2)$ & 72 & $40.4(3.1)$ & $115.4(14.0)$ & NR & NR & 40 & $\mathrm{NR}$ \\
\hline \multirow[t]{2}{*}{$\begin{array}{l}\text { Dixon } \\
2008^{25}\end{array}$} & $\begin{array}{c}\text { Bariatric surgery } \\
\text { (AGB) }\end{array}$ & 30 & $46.6(7.4)$ & 50 & $37(2.7)$ & $105.6(13.8)$ & 100 & $<2$ & 97 & 93 \\
\hline & Control & 30 & $47.1(8.7)$ & 57 & $37.2(2.5)$ & $105.9(14.2)$ & 100 & $<2$ & 97 & 90 \\
\hline \multirow[t]{2}{*}{$\begin{array}{l}\text { Dixon } \\
2012^{22}\end{array}$} & $\begin{array}{c}\text { Bariatric surgery } \\
\text { (AGB) }\end{array}$ & 30 & $47.4(8.8)$ & 43 & $46.3(6.0)$ & $134.9(22.1)$ & 33 & NR & 63 & 50 \\
\hline & Control & 30 & $50.0(8.2)$ & 40 & $43.8(4.9)$ & $126.0(19.3)$ & 33 & $N R$ & 80 & 57 \\
\hline \multirow[t]{2}{*}{$\begin{array}{l}\text { Mingrone } \\
2002^{17}\end{array}$} & $\begin{array}{c}\text { Bariatric surgery } \\
\text { (BPD) }\end{array}$ & 46 & $37.4(4.6)$ & 85 & $48.2(5.0)$ & $133.9(16.2)$ & NR & NR & NR & NR \\
\hline & Control & 33 & $37.4(4.6)$ & 88 & $48.2(7.7)$ & 130.9 (24.5) & NR & NR & NR & $\mathrm{NR}$ \\
\hline \multirow[t]{2}{*}{$\begin{array}{l}\text { Heindorff } \\
1997^{26}\end{array}$} & $\begin{array}{c}\text { Bariatric surgery } \\
\text { (AGB) }\end{array}$ & 8 & Range $22-41$ & 75 & Range $43-54$ & NR & NR & $N R$ & NR & NR \\
\hline & Control & 8 & Range $21-43$ & 15 & Range $40-56$ & NR & NR & NR & NR & NR \\
\hline
\end{tabular}

$\mathrm{AGB}=$ adjustable gastric banding; $\mathrm{BMI}=$ body mass index, BPD=biliopancreatic diversion, NR=not reported, RYGB=Roux-en-Y gastric bypass.

*In three-arm studies Mingrone 2012 and Schauer 2012 the two bariatric surgery groups were combined, and in Liang 2013 the two non-surgical groups were combined.

†This is the time point before RYGB and 4 months after extensive weight-loss programme in the bariatric surgery group. 
Table 2/ Summary of risk of bias assessment for the 11 studies included in meta-analysis: allocation and blinding

\begin{tabular}{|c|c|c|c|c|c|c|c|}
\hline \multirow[b]{2}{*}{ Study } & \multirow{2}{*}{$\begin{array}{l}\text { Sequence } \\
\text { generation } \\
\text { adequate }\end{array}$} & \multirow{2}{*}{$\begin{array}{l}\text { Allocation } \\
\text { concealed }\end{array}$} & \multicolumn{5}{|c|}{ Blinding } \\
\hline & & & Patients & Healthcare providers & Data collectors* & Outcome adjudicators ${ }^{*}$ & Data analysts* \\
\hline Mingrone $2012^{16}$ & Yes & Yes & No & No & Yes & Yes & Yes \\
\hline Schauer $2012^{18}$ & Yes & Yes & No & No & No & No & No \\
\hline Reis $2010^{20}$ & Yes & Yes & No & No & No & No & No \\
\hline Ikramuddin $2013^{19}$ & Yes & Yes & No & No & Yes & Yes & Unclear \\
\hline Liang $2013^{24}$ & Yes & Unclear & No & No & Unclear & Unclear & Unclear \\
\hline O'Brien $2006^{23}$ & Yes & Yes & No & No & Unclear & Unclear & Unclear \\
\hline O'Brien $2010^{21}$ & Yes & Unclear & No & No & Unclear & Unclear & Unclear \\
\hline Dixon $2008^{25}$ & Yes & Unclear & No & No & Unclear & Unclear & Unclear \\
\hline Dixon $2012^{22}$ & Yes & Unclear & No & No & Unclear & Unclear & Unclear \\
\hline Mingrone $2002^{17}$ & Yes & Yes & No & No & Yes & Yes & Yes \\
\hline Heindorff $1997^{26}$ & Unclear & Unclear & No & No & Unclear & Unclear & Unclear \\
\hline
\end{tabular}


Table 3| Summary of risk of bias assessment for the 11 studies included in meta-analysis: analysis and reporting

\begin{tabular}{|c|c|c|c|c|c|c|c|}
\hline \multirow[b]{2}{*}{ Study } & \multirow{2}{*}{$\begin{array}{l}\text { All randomised } \\
\text { patients } \\
\text { analysed }\end{array}$} & \multirow[b]{2}{*}{$\begin{array}{l}\text { Analysed as } \\
\text { randomised }\end{array}$} & \multicolumn{3}{|c|}{ Incomplete outcome data addressed } & \multirow[b]{2}{*}{$\begin{array}{l}\text { Free of selective } \\
\text { reporting }\end{array}$} & \multirow[b]{2}{*}{$\begin{array}{l}\text { Exact data } \\
\text { available }^{*}\end{array}$} \\
\hline & & & Continuous data & Diabetes remission & $\begin{array}{l}\text { Metabolic syndrome } \\
\text { remission }\end{array}$ & & \\
\hline Mingrone $2012^{16}$ & No & Yes & Yes & Yes & NA & Yes & Yes \\
\hline Schauer $2012^{18}$ & Yes & Yes & Yes & Yes & Yes & Yes & Yes \\
\hline Reis $2010^{20}$ & Yes & Yes & Yes & NA & NA & Unclear & Yes \\
\hline Ikramuddin $2013^{19}$ & Yest & Yes & Yest & NA & NA & Yes & Yes \\
\hline Liang $2013^{24}$ & No & Yes & No & No & NA & Unclear & No \\
\hline O'Brien $2006^{23}$ & No & Yes & No & NA & No & Yes & Yes \\
\hline O'Brien $2010^{21}$ & No & Yes & No & NA & No & Yes & Yes \\
\hline Dixon $2008^{25}$ & Yes & Yes & No & Yes & No & Yes & Yes \\
\hline Dixon $2012^{22}$ & Yes & Yes & Yes & NA & Yes & Yes & Yes \\
\hline Mingrone $2002^{17}$ & Yes & Yes & Yes & NA & NA & Yes & Yes \\
\hline Heindorff $1997^{26}$ & Yes & Yes & Yes & NA & NA & Unclear & Yes \\
\hline
\end{tabular}

$\mathrm{NA}=$ Not applicable, because outcome was not addressed in the study.

*With regard to body weight loss.

†For data in the publication yes, but not for data additionally obtained by contacting study authors. 


\section{Figures}

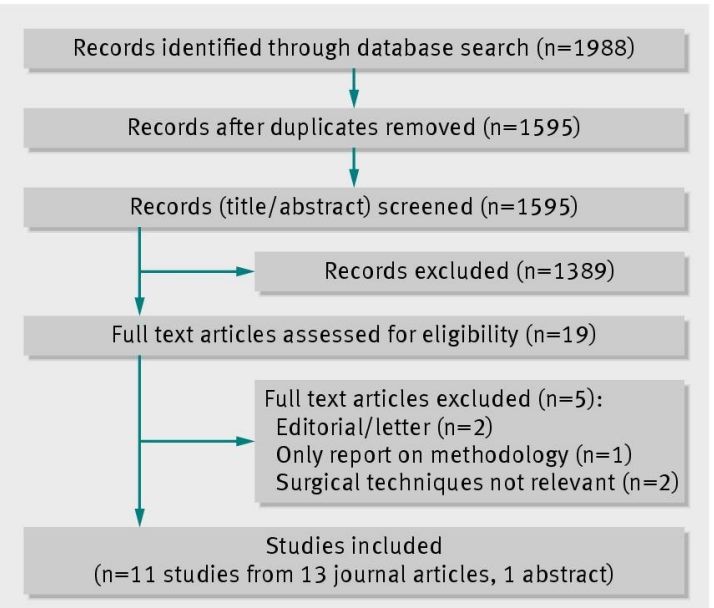

Fig 1 Results on information search. ( ${ }^{*}$ Relevant bariatric surgery techniques were Roux-en-Y gastric bypass, adjustable gastric banding, sleeve gastrectomy, and biliopancreatic diversion with or without duodenal switch)

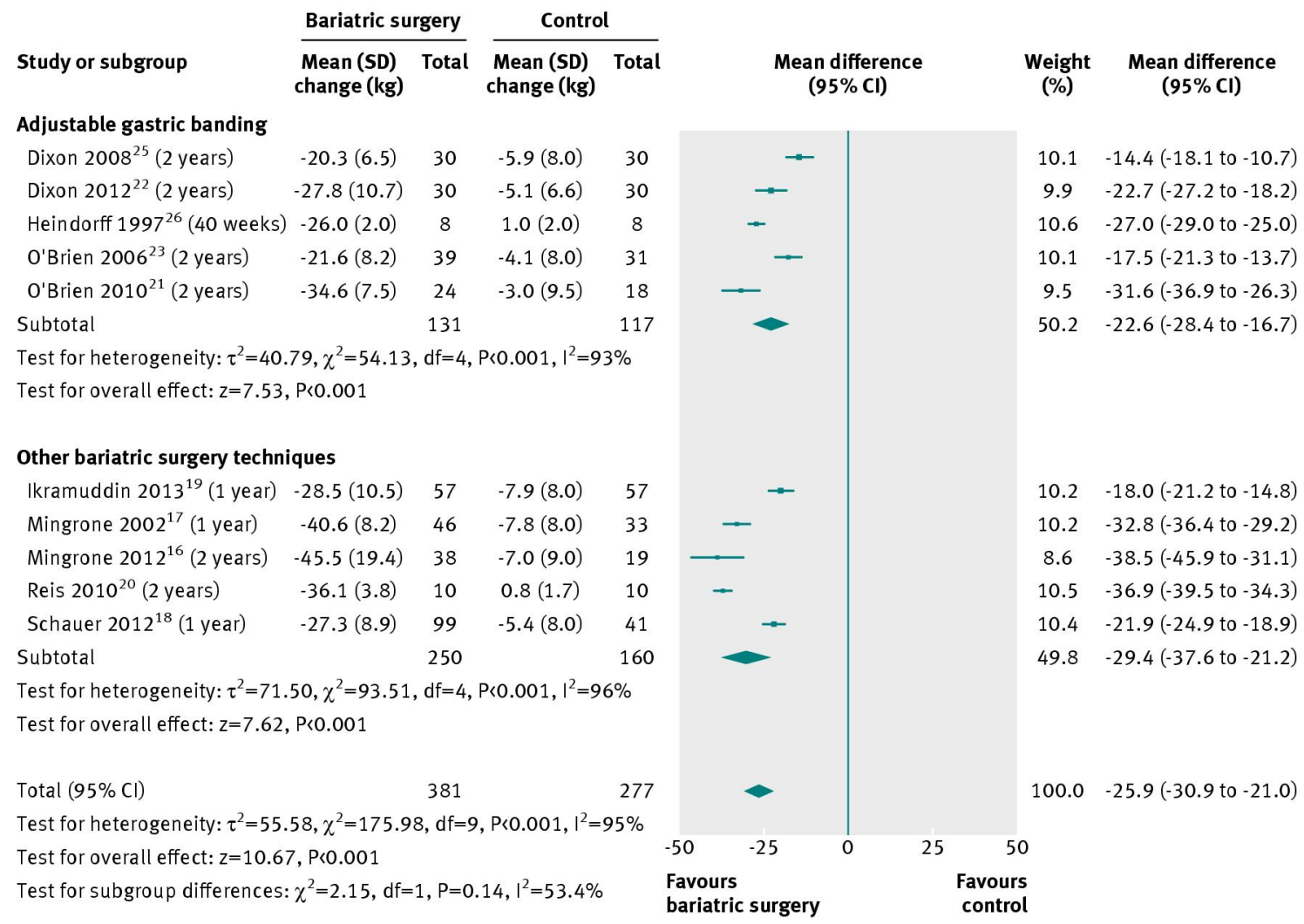

Fig 2 Mean change in body weight (kg) after bariatric surgery versus non-surgical treatment (control) for obesity. Subgroup analysis was done for the studies that used adjustable gastric banding versus other bariatric surgery techniques. (Differences in mean change in body weight calculated by inverse variance statistical method of random effects model) 


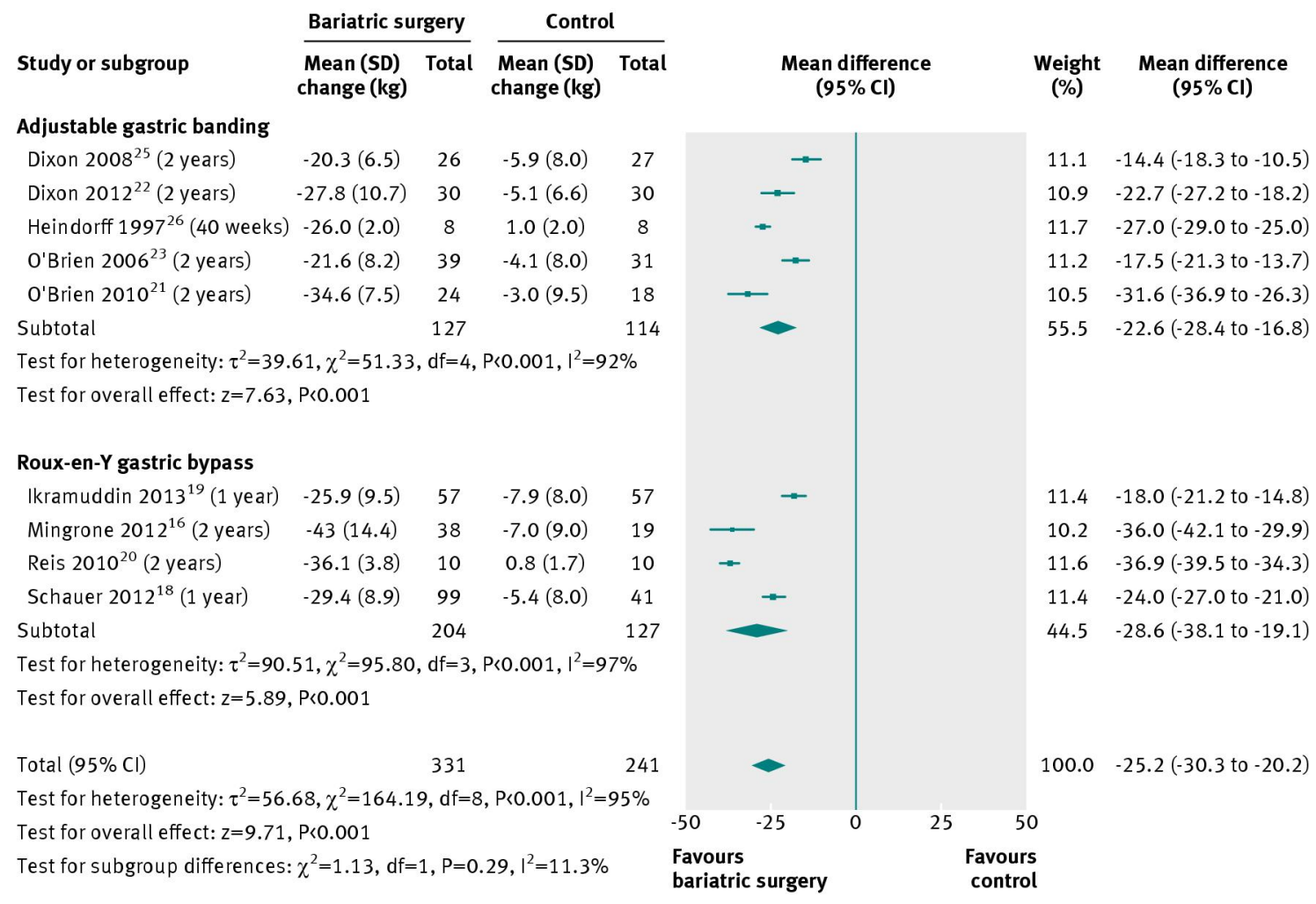

Fig 3 Mean change in body weight $(\mathrm{kg})$ after adjustable gastric banding or Roux-en- $Y$ gastric bypass versus non-surgical treatment (control) for obesity. Subgroup analysis was done for the studies that used adjustable gastric banding versus Roux-en-Y gastric bypass. (Differences in mean change in body weight calculated by inverse variance statistical method of random effects model)

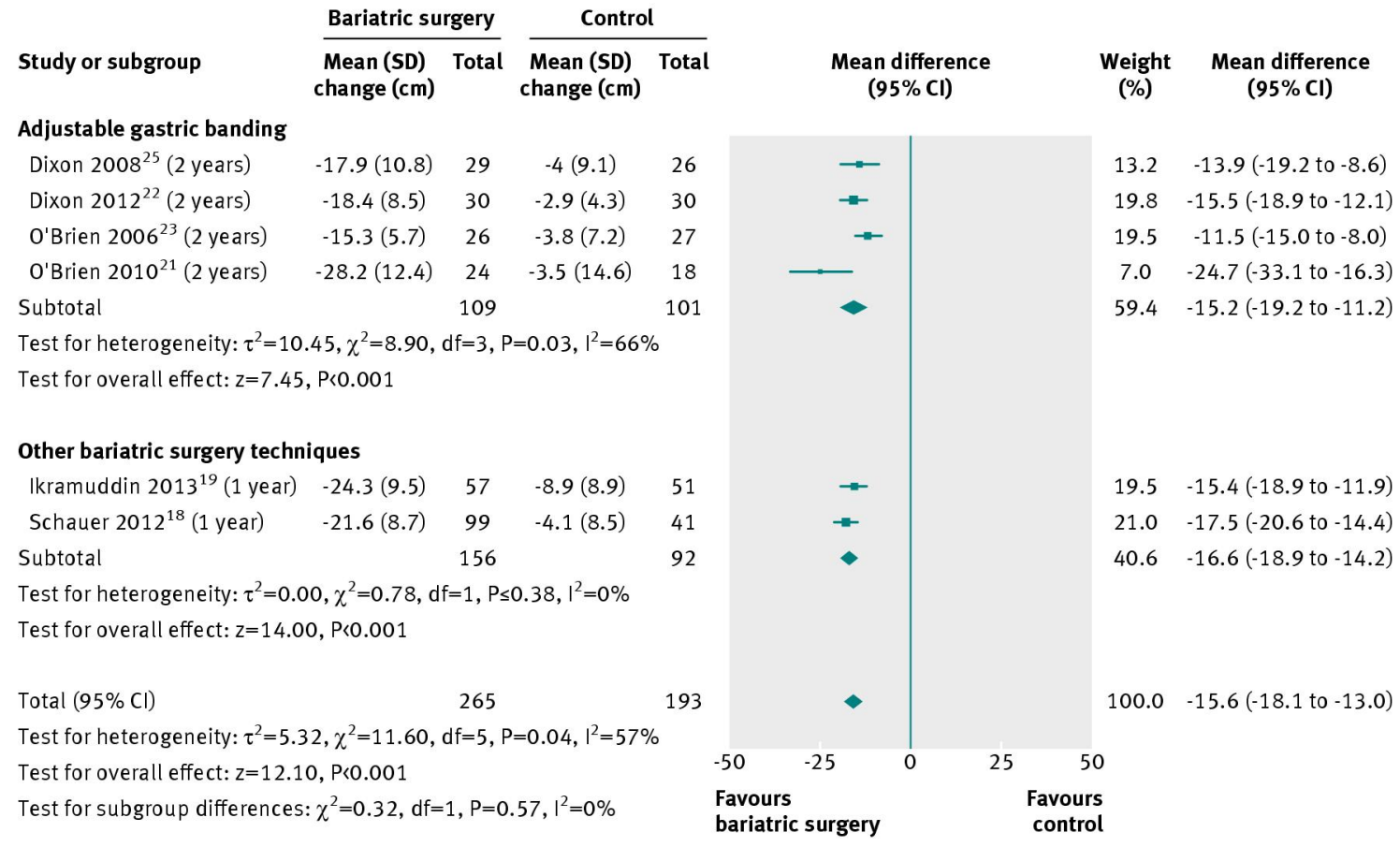

Fig 4 Mean change in $(\mathrm{cm})$ after bariatric surgery versus non-surgical treatment (control) for obesity. Subgroup analysis was done for the studies that used adjustable gastric banding versus other bariatric surgery techniques. (Differences in mean change in waist circumference calculated by inverse variance statistical method of random effects model) 


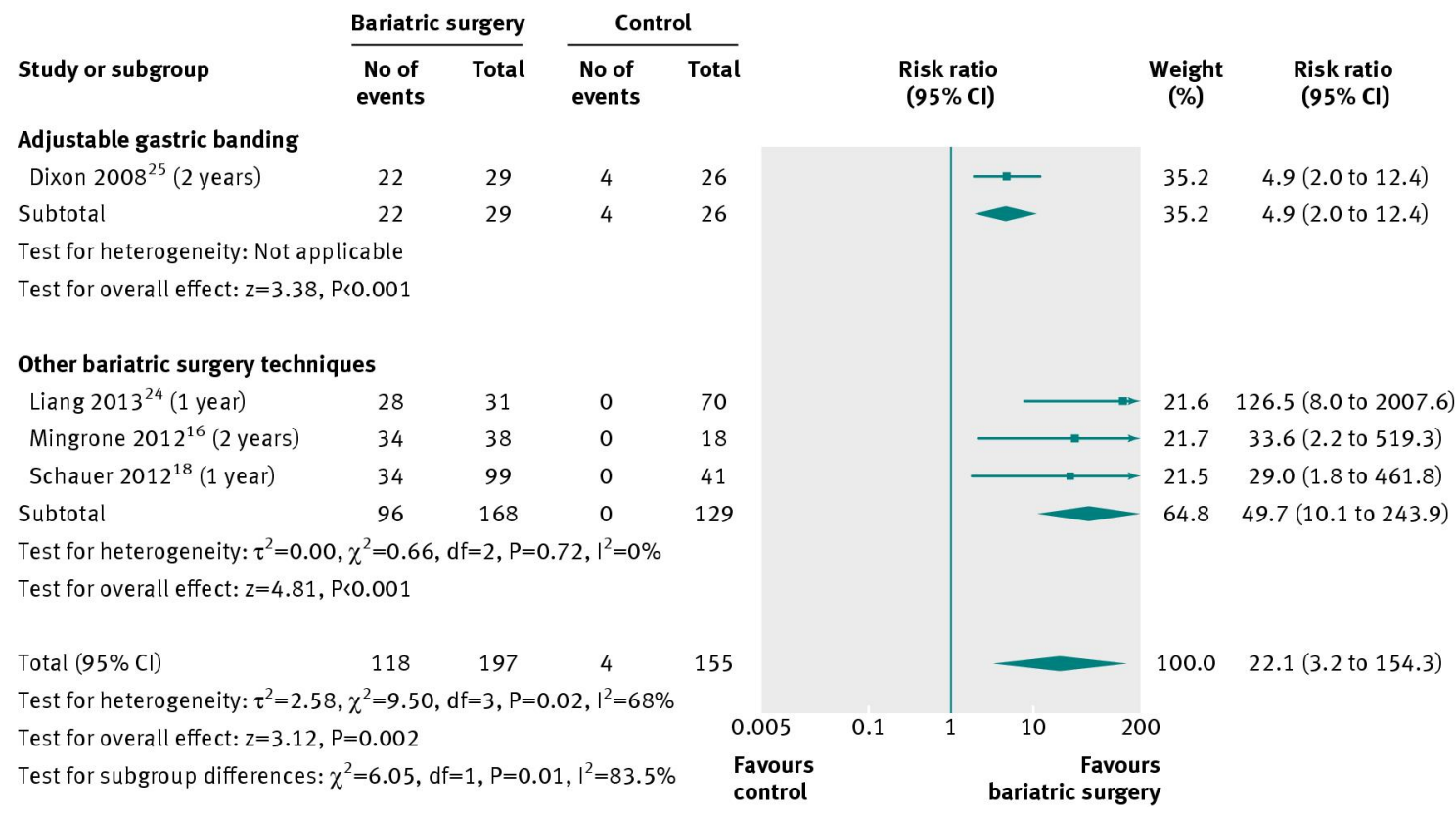

Fig 5 Type 2 diabetes remission after bariatric surgery versus non-surgical treatment (control) for obesity. Subgroup analysis was done for the studies that used adjustable gastric banding versus other bariatric surgery techniques. (Risk ratios calculated by Mantel-Haenzel statistical method of a random effects model; missing data were not addressed (complete case analysis))

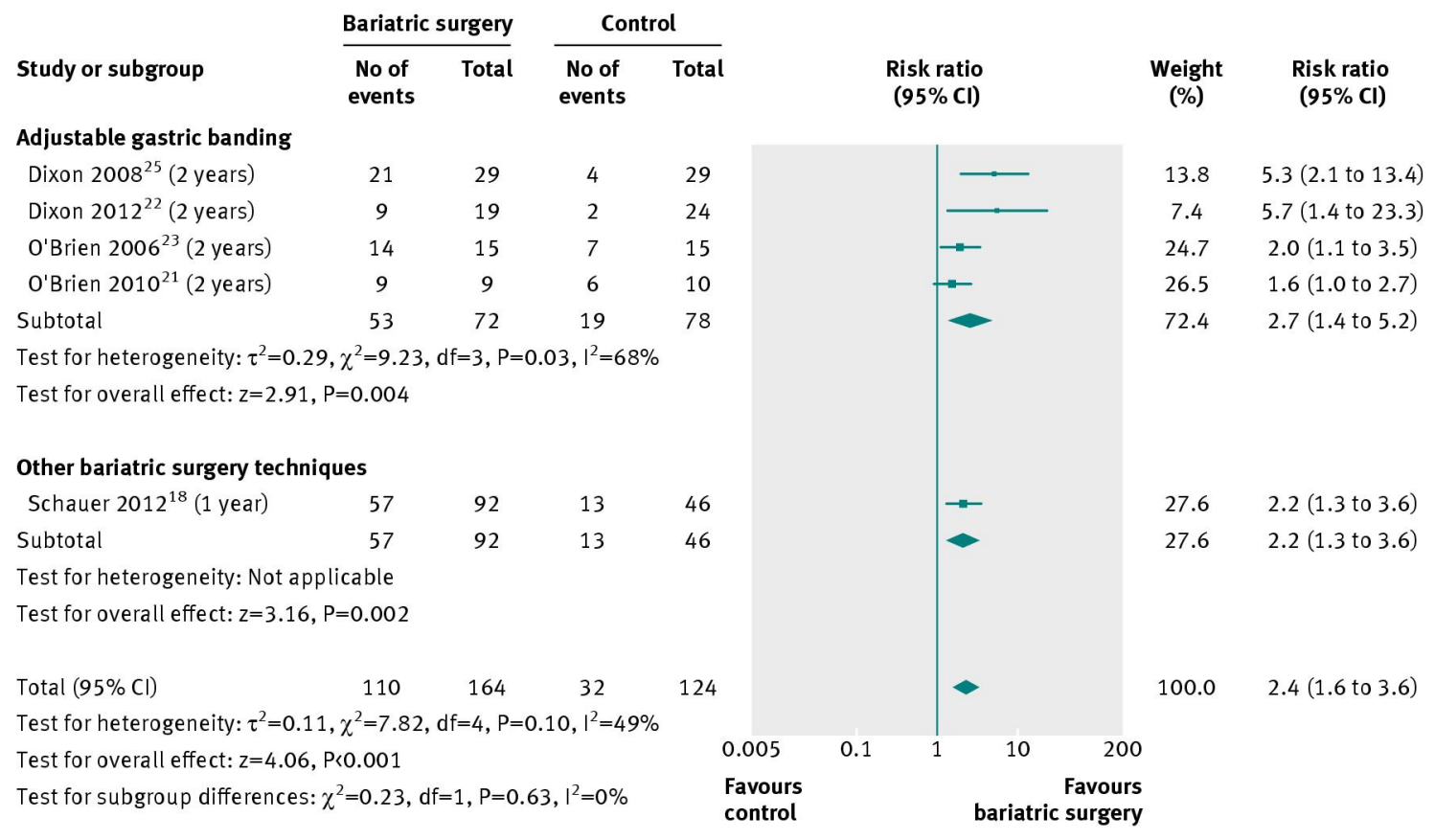

Fig 6 Metabolic syndrome remission after bariatric surgery versus non-surgical treatment (control) for obesity. Subgroup analysis was done for the studies that used adjustable gastric banding versus other bariatric surgery techniques. (Risk ratios calculated by Mantel-Haenzel statistical method of a random effects model; missing data were not addressed (complete case analysis)) 


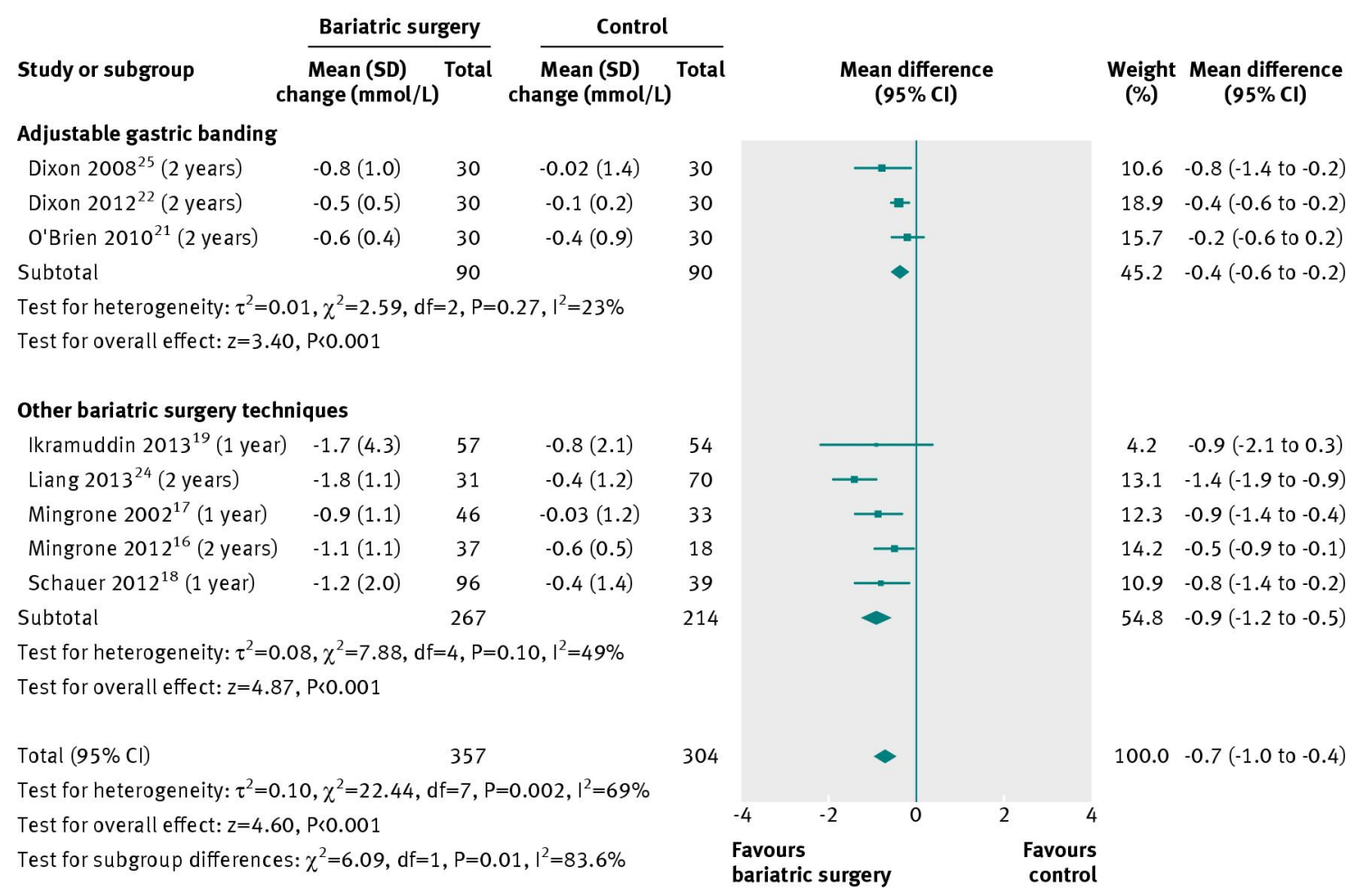

Fig 7 Change in plasma triglyceride concentrations (mmol/L) after bariatric surgery versus non-surgical treatment (control) for obesity. Subgroup analysis was done for the studies that used adjustable gastric banding versus other bariatric surgery techniques. (A conversion factor of 0.01129 used to convert values from $\mathrm{mg} / \mathrm{dL}$ to $\mathrm{mmol} / \mathrm{L}$. Differences in mean change in triglyceride concentration calculated by inverse variance statistical method of random effects model)

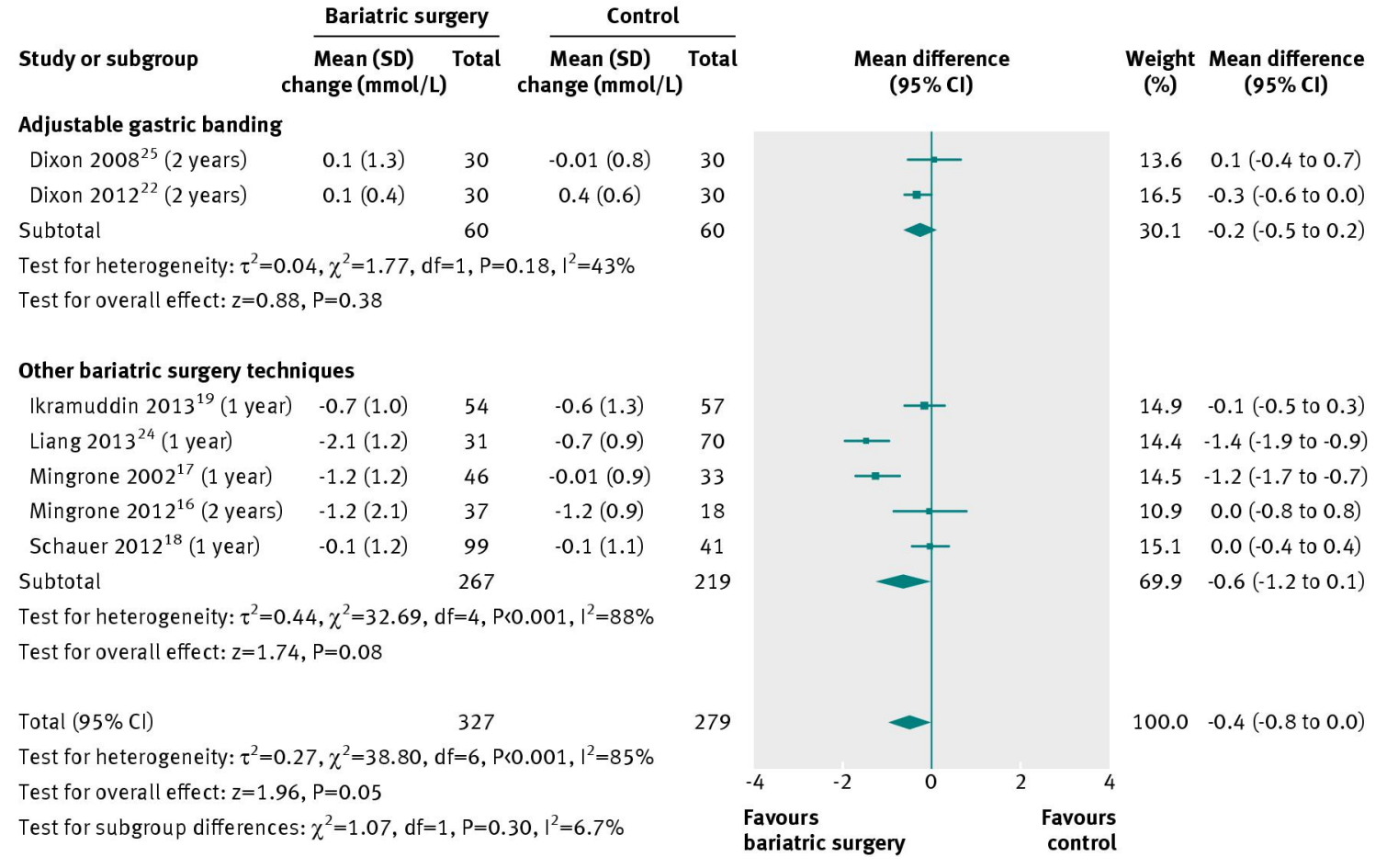

Fig 8 Change in plasma total cholesterol concentration ( $\mathrm{mmol} / \mathrm{L})$ after bariatric surgery versus non-surgical treatment (control) for obesity. Subgroup analysis was done for the studies that used adjustable gastric banding versus other bariatric surgery techniques. (A conversion factor of 0.02586 was used to convert values from $\mathrm{mg} / \mathrm{dL}$ to $\mathrm{mmol} / \mathrm{L}$. Differences in mean change in cholesterol concentration calculated by inverse variance statistical method of random effects model) 


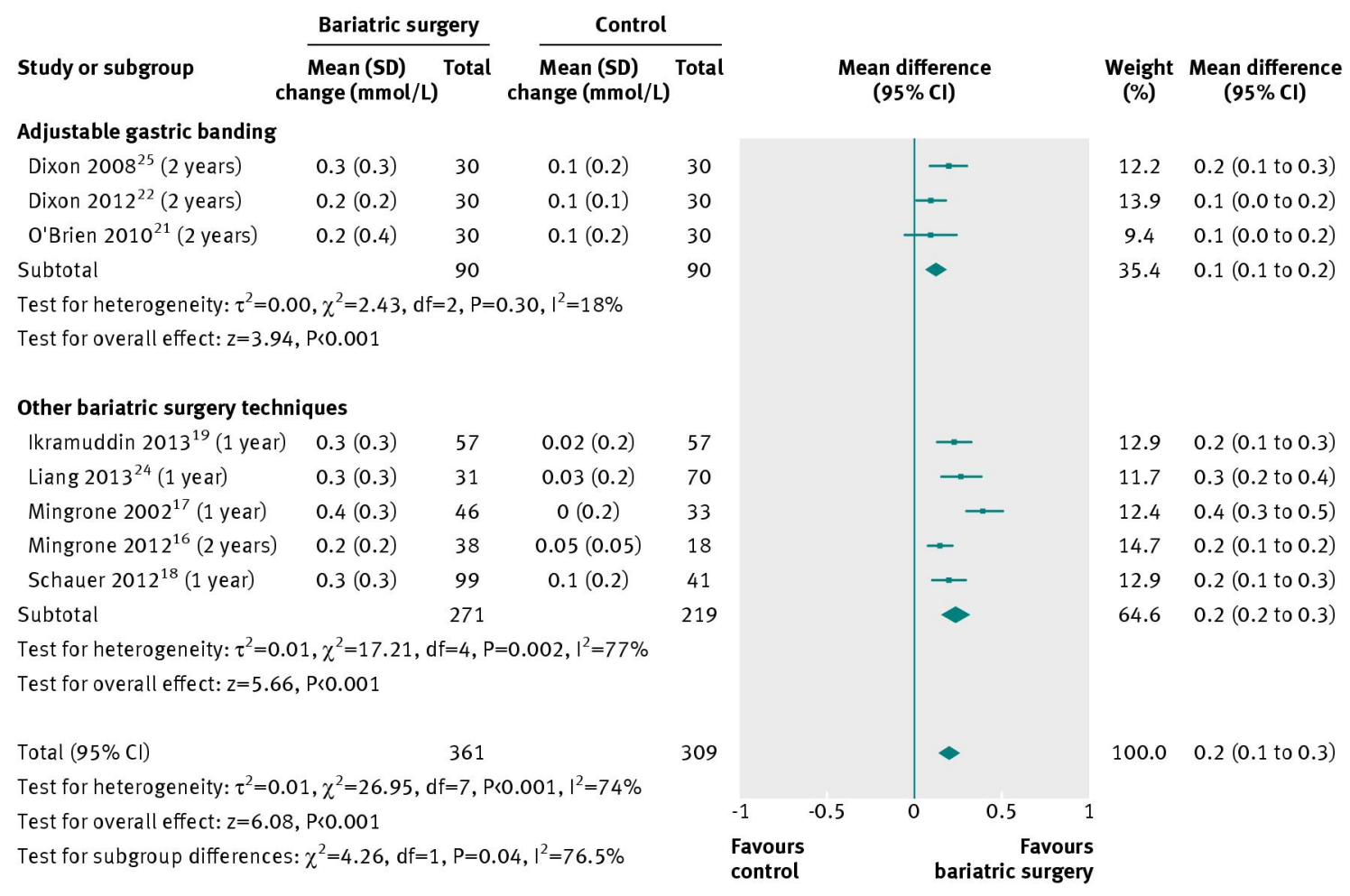

Fig 9 Change in high density lipoprotein cholesterol concentrations ( $\mathrm{mmol} / \mathrm{L})$ after bariatric surgery versus non-surgical treatment (control) for obesity. Subgroup analysis was done for the studies that used adjustable gastric banding versus other bariatric surgery techniques. (A conversion factor of 0.02586 was used to convert values from $\mathrm{mg} / \mathrm{dL}$ to $\mathrm{mmol} / \mathrm{L}$. Differences in mean change in concentration calculated by inverse variance statistical method of random effects model)

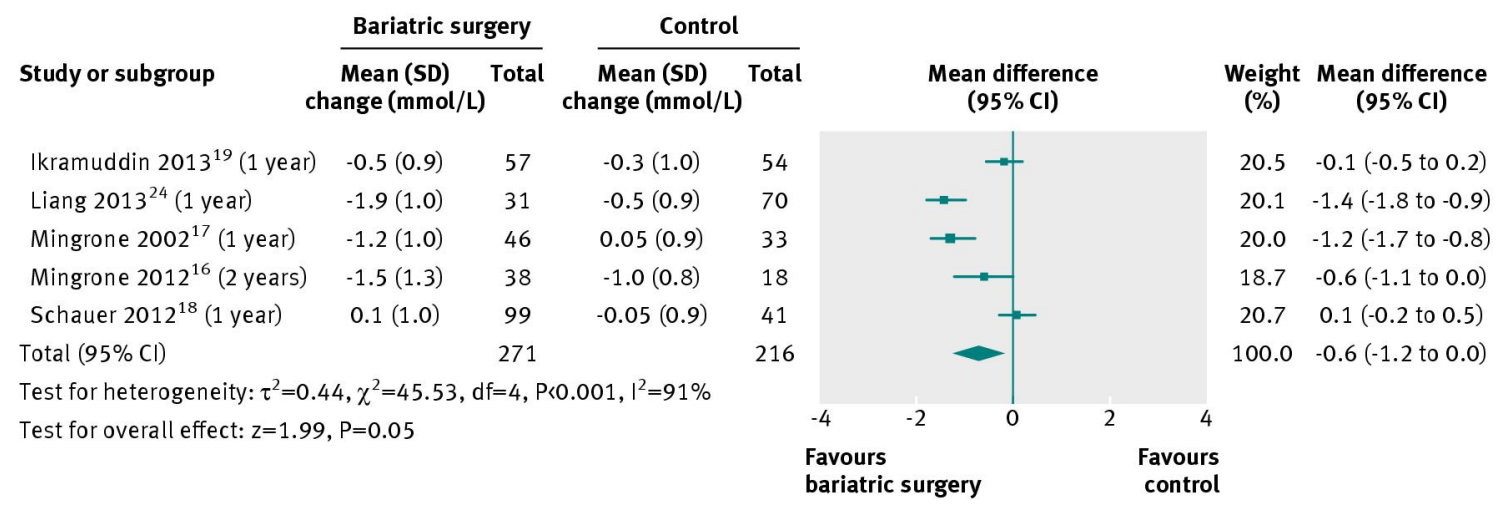

Fig 10 Change in low density lipoprotein cholesterol concentrations ( $\mathrm{mmol} / \mathrm{L})$ after bariatric surgery versus non-surgical treatment (control) for obesity. (A conversion factor of 0.02586 was used to convert values from $\mathrm{mg} / \mathrm{dL}$ to $\mathrm{mmol} / \mathrm{L}$. Differences in mean change in concentration calculated by inverse variance statistical method of random effects model) 


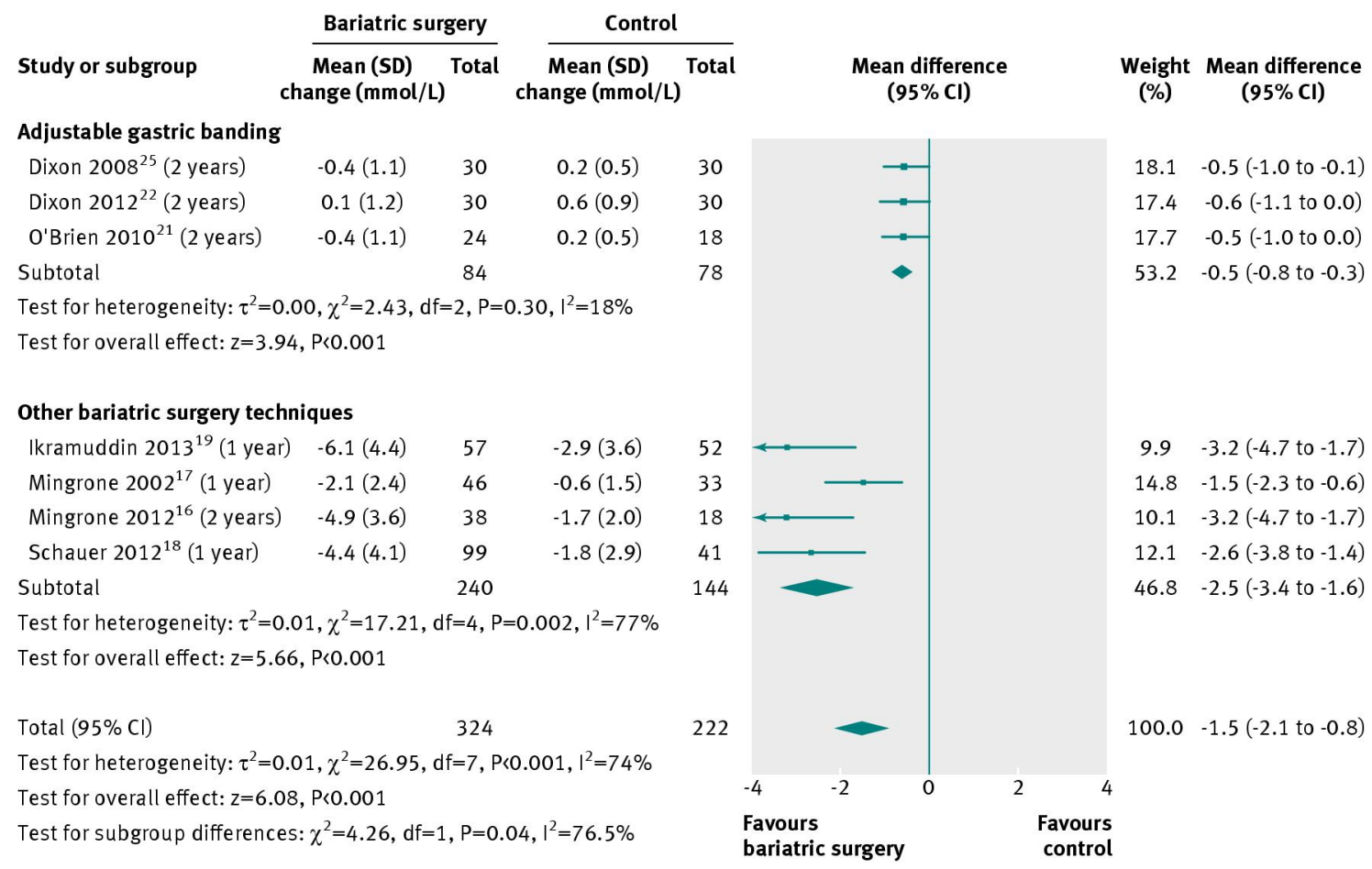

Fig 11 Change in plasma fasting glucose concentrations $(\mathrm{mmol} / \mathrm{L})$ after bariatric surgery versus non-surgical treatment (control) for obesity. Subgroup analysis was done for the studies that used adjustable gastric banding versus other bariatric surgery techniques. (Differences in mean change in concentration calculated by inverse variance statistical method of random effects model)

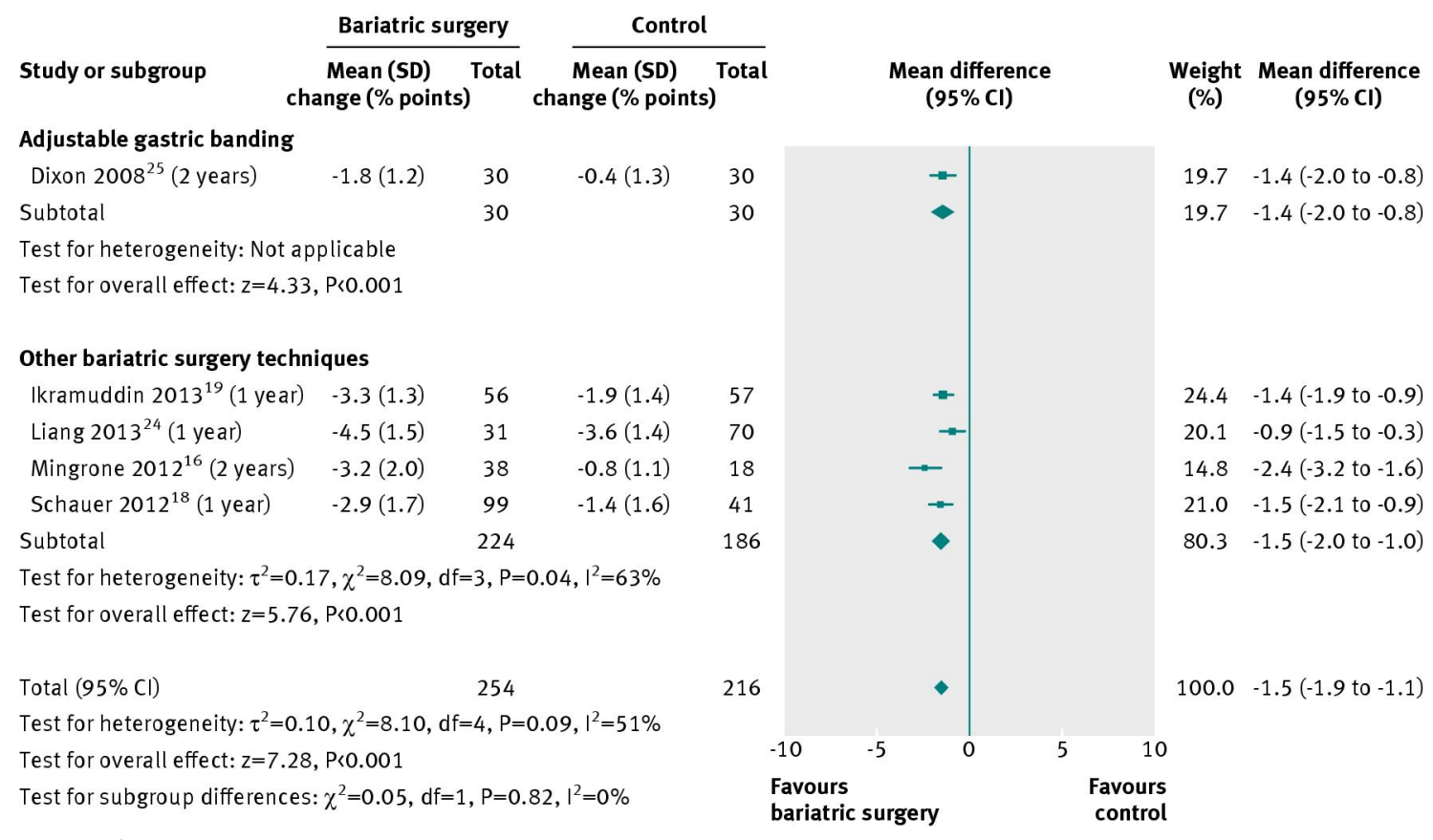

Fig 12 Change in glycated haemoglobin $\mathrm{HbA}_{1 \mathrm{c}}$ levels (\% points) after bariatric surgery versus non-surgical treatment (control) for obesity. The mean change in $\mathrm{HbA}_{1 \mathrm{c}}$ was pooled for the studies that included diabetic participants only. Subgroup analysis was done for the studies that used adjustable gastric banding versus other bariatric surgery techniques. (Differences in mean change in concentration calculated by inverse variance statistical method of random effects model) 